Research Article

\title{
Optimal Pricing Strategies in a Product and Service Supply Chain with Extended Warranty Service Competition considering Retailer Fairness Concern
}

\author{
Du Zhao $\mathbb{D}^{1},{ }^{1}$ Xumei Zhang $\mathbb{D}^{1},{ }^{1}$ Tinghai Ren $\mathbb{D}^{2},{ }^{2}$ and Hongyong Fu $\mathbb{i}^{3}$ \\ ${ }^{1}$ School of Economics and Business Administration, Chongqing University, Chongqing 400044, China \\ ${ }^{2}$ School of Business, Guizhou University of Finance and Economics, Guiyang 550025, China \\ ${ }^{3}$ China Research Institute of Enterprise Governed By Law, Southwest University of Political Science and Law, \\ Chongqing 401120, China
}

Correspondence should be addressed to Xumei Zhang; xmzhang66@126.com and Hongyong Fu; fuhongyong@foxmail.com

Received 25 March 2019; Revised 10 May 2019; Accepted 20 May 2019; Published 27 August 2019

Academic Editor: Emilio Gómez-Déniz

Copyright ( $\odot 2019$ Du Zhao et al. This is an open access article distributed under the Creative Commons Attribution License, which permits unrestricted use, distribution, and reproduction in any medium, provided the original work is properly cited.

\begin{abstract}
This paper examines optimal pricing in a two-tier product and service supply chain consisting of a manufacturer and a retailer in the context of vertical competition in extended warranty in two cases: one considering the retailer's fairness concerns and one without considering the retailer's fairness concerns. A manufacturer-dominated product and service supply chain game-theoretic model on the Stackelberg model is developed to analyse how the level of vertical competition in extended warranty service and the intensity of a retailer's fairness concerns influence the optimal pricing of products and extended warranties for the manufacturer and retailer. This study finds the following: (i) Two parties of the supply chain employ differential pricing strategies for extended warranties when the retailer has fairness concerns. (ii) Compared to the same pricing strategies for extended warranty service when the retailer has no fairness concerns, the increase of competition intensity of vertical extended warranty service will enlarge the price difference of extended warranty service. Meanwhile, it is the intensity of fairness concerns that determines the influences of retailer's fairness concerns on the price difference of extended warranties. (iii) If no fairness concerns are raised, an increase in the level of vertical competition in extended warranty service would benefit both supply chain parties, rather than hurting their profit. If the retailer is fair-minded, its fairness utility increases when the intensity of the fairness concerns rises in a reasonable range and decreases when the intensity exceeds the reasonable range, but for the manufacturer, its profits will be damaged as long as the retailer raises fairness concerns.
\end{abstract}

\section{Introduction}

As market competition intensifies, the profits generated by manufacturers and retailers through traditional product production and sales are gradually reduced, which forces them to actively seek new profit drivers. A case in point is their shift to the innovative business model of offering products and related services at the same time [1]. Among a variety of services delivered along with products, extended warranties have become a new profit driver sought after by both manufacturers and retailers [2]. Unlike the traditional warranty service, an extended warranty service is a prolonged, paid warranty offered to consumers in addition to the standard warranty on a product [3]. Currently, both manufacturers and retailers have begun to offer extended warranties to obtain more profits. For example, Germanybased Siemens, Japan-based Panasonic, and other famous home appliance manufacturers sell extended warranties to consumers who purchase their products. In China, Suning, Gome, and other large home appliance retailers also offer extended warranties as a tied service for their products by leveraging their channel advantages. As a result, manufacturers and their downstream retailers in the same product and service supply chain compete fiercely with each other vertically for sales and market share of homogeneous extended warranties sales. 
It is worth noting that competition in the extended warranty service market is based on products. However, the relationship between a manufacturer and a retailer within a supply chain is much more about upstream and downstream partnership regarding production and sales of specific products. This requires ensuring that both the manufacturers and retailers within a product and service supply chain obtain the optimal benefits. The key to solving this issue lies in making optimal pricing decisions for products and services. In optimal pricing decisions, the dominant manufacturer tends to play a powerful role in setting prices $[4,5]$, while often leads the retailer in a weak position to raise fairness concerns. This inevitably further influences optimal pricing decisions [6]. To address the issue, this paper discusses how a retailer's fairness concerns influence the optimal pricing decisions for products and services in a product and service supply chain with vertical competition in extended warranty service.

At present, the research on extended warranties has gone beyond extended warranties offered by a single enterprise [7-9] to include multiple supply chain members. Jiang and Zhang [10] studied the impact of a retailer's extended warranties on the basic warranties from a manufacturer. Heese [11] examined the warranty strategies of manufacturers and the extended warranty strategies of retailers in the context of two competing manufacturers selling products through a common retailer. The literature $[10,11]$ puts its focus on the impact of a retailer's extended warranties on a manufacturer's basic warranties instead of on the pricing of extended warranties on products. Li et al. [12] compared and analysed the extended warranties provided separately by a manufacturer and a retailer within a two-tier supply chain in terms of the length, price, and profit of the extended warranties. Cohen and Whang [13] discussed the optimal pricing of products and extended warranties for manufacturers and third-party service providers in two cases: the one with the extended warranties provided by manufacturers and the other one with the extended warranties provided by third-party service providers. Li et al. and Cohen and Whang $[12,13]$ studied the pricing of extended warranties in a supply chain, whose members, however, do not compete with each other. Chen et al. [14] examined optimal competing and collaborating strategy in a complex supply chain consisting by two manufacturers who manufacture substitutive products and purchase a key component from the other. Chen et al. [14] studied the competition, but it is not warranty competition. In the supply chain consisting of a manufacturer providing warranties and two competing retailers providing extended warranties, Bian et al. [15] explored the pricing of extended warranties by the two retailers against the backdrop of horizontal competition between each other. This paper extends the work of Bian et al. [15] by introducing vertical competition in extended warranty between a manufacturer and its downstream retailer in a supply chain. It also considers how fairness concern of the retailer in the weak position in a product and service supply chain influences the optimal pricing of products and extended warranties.
The paper also covers fairness concerns in supply chains. Camerer and Thaler [16] proved through the ultimatum game that people punish others for unfair behaviour even when it is costly for them to do so. Ho and Zhang [17] confirmed through experimental research that there is fairness concern behaviour in supply chain contracts. In the field of operational research and management science, research on supply chain fairness concerns generally focuses on two areas. The first one is the impact of fairness concerns on traditional supply chain contract design. Cui et al. [6] are among the first to use the mathematical model to study fairness concerns in a two-tier supply chain. They find that when both the manufacturer and the retailer have advantageous and disadvantageous inequity aversions simultaneously, a simple wholesale price contract can make supply chain coordinated under certain conditions; CaliskanDemirag et al. [18] extended the work of Cui et al. [6] to a nonlinear demand function and found that if both the manufacturer and the retailer have advantageous and disadvantageous inequity aversions simultaneously in a nonlinear demand setting, the supply chain members could also achieve coordination. In addition, the exponential demand function requires less stringent conditions than the linear demand to achieve supply chain coordination. Wu and Niederhoff [19] extended the analysis of supply chain fairness concerns to the random-demand newsvendor model in which they studied the impact of fairness concerns on supply chain coordination. The second attractive area of research on supply chain fairness concerns is the impact of fairness concerns on optimal pricing decisions in a supply chain. $\mathrm{Ma}$ et al. [20] studied the impact of a retailer's fairness concerns on recovery rates, sales efforts, and profits in a closed-loop supply chain environment where the product demand is sensitive to the retailer's sales effort. In the low-carbon supply chain setting, Zhou et al. [21] examined the impact of a retailer's fairness concerns on the supply chain pricing strategies under both cooperative advertising contracts and cooperative advertising and emission reduction cost-sharing contracts. Ma et al. and Zhou et al. [20, 21] studied the impact of fairness concerns in supply chains on optimal pricing of products, but not of services. Liu et al. [22] investigated the optimal allocation strategy of logistics service orders in a service supply chain composed of a logistics service integrator and several logistics service providers (LSPs) based on the LSPs' fairness concern preferences and demand updating. Du and Han [23] analysed optimal pricing strategies under the impact of fairness concerns in the logistics service supply chain in which the market demand is affected by the price and quality defect guarantee of logistics services at the same time. Liu et al. and Du and Han $[22,23]$ studied the impact of fairness concerns on the optimal pricing of services, but not of products. Wang et al. [24] considered a mobile phone supply chain (MPSC) consisting of a service operator and a handset manufacturer and analysed the influence of the nature and level of both the handset manufacturer's fairness concerns and the operator's fairness concerns on the pricing decision. $\mathrm{Li}$ and $\mathrm{Li}$ [25] analysed the impacts of a retailer's fairness concerns on the pricing of products and value-added services as well as on 
channel conflict in a dual-channel supply chain in which a manufacturer sells products through a direct channel and also through a traditional retail channel in which the manufacturer's downstream retailer has fairness concerns and provides value-added services to consumers. Wang et al. [24] and $\mathrm{Li}$ and $\mathrm{Li}$ [25] studied the impact of fairness concerns on the pricing decisions for both products and services, but without considering service competition. This study extends the current literature by investigating the optimal pricing of products and services at the same time in a product and service supply chain with vertical competition in extended warranty service.

Drawing on the extant literatures, this paper considers retailers' fairness concern preference and the intensity of vertical competition in extended warranty service between retailers and manufacturers when studying the optimal pricing decisions for products and services in a product and service supply chain composed of a manufacturer and retailer. We intend to answer the following questions.

What are the optimal pricing decisions for products and services in a product and service supply chain when the retailer does not have fairness concerns?

What are the optimal pricing decisions for products and services in a product and service supply chain when the retailer has fairness concerns compared with no fairness concerns considered?

How do the level of the retailer's fairness concerns and the level of vertical competition in extended warranty service affect the optimal pricing of products and services in a product and service supply chain?

The rest of this study is organized as follows. In Section 2, the assumptions and questions related to this paper are described. In Section 3, the model used in this paper is solved in two situations: when the retailer has fairness concerns and when the retailer has no fairness concerns. The optimal pricing strategies for products and services in a product and service supply chain in both situations are analysed. Section 4 verifies the main conclusions of the paper using numerical examples. Conclusions and future work are presented in the last section.

\section{Model Assumptions}

We consider a two-tier product and service supply chain consisting of a manufacturer and a retailer. In the supply, consumers purchase products from the retailer to satisfy their needs, the retailer orders products from the manufacturer based on the consumers' needs, and the manufacturer strives to manufacture products to meet the retailer's order requirements. This creates a supply-demand flow of products. Beyond that, the supply chain also has a supply-demand flow of extended warranties on the products. To better meet consumer demand and improve user experience, both the manufacturer and retailer can provide homogeneous extended warranties. This means that there is vertical competition in an extended warranty service between the manufacturer and its downstream retailer in the supply chain.
In Figure 1, $w$ and $p_{\mathrm{sm}}$ are the product wholesale price and extended warranty service price determined by the manufacturer, respectively. $p_{\mathrm{p}}$ and $p_{\mathrm{sr}}$ are the product retail price and extended warranty service price determined by the manufacturer, respectively.

We assume that the market demand for a specific product from the manufacturer and the retailer is $D_{\mathrm{p}}=a-p_{\mathrm{p}}$, where $a(a>0)$ is the market size. This additive demand function has been widely used by Chen et al. [26] and in other literature. Since consumers decide whether to purchase an extended warranty service only after purchasing a product, their demand for extended warranties is surely not higher than their demand for products. Without loss of generality, the demand for a specific extended warranty service from the retailer and the manufacturer can be expressed as follows:

$$
\begin{aligned}
& D_{\mathrm{sr}}=\left(a-p_{\mathrm{p}}\right)-p_{\mathrm{sr}}+\beta p_{\mathrm{sm}}, \\
& D_{\mathrm{sm}}=\left(a-p_{\mathrm{p}}\right)-p_{\mathrm{sm}}+\beta p_{\mathrm{sr}},
\end{aligned}
$$

where $\beta(0<\beta<1)$ is the level of vertical competition in extended warranty service between the manufacturer and retailer.

This paper focuses on analysing how the level of vertical competition in extended warranty service and a retailer's fairness concern preference affect the optimal pricing of products and services of the retailer and manufacturer. For ease of exposition, the manufacturer's cost of production and the retailer's cost of sales can be set to zero [27]. In addition, the service costs of the manufacturer and retailer depend primarily on their respective service capabilities, which usually remain unchanged within a certain period of time, so the service costs of both parties can also be set to zero [27].

From the above description and assumptions, the manufacturer's profit function can be expressed as follows:

$$
\pi_{\mathrm{m}}=w\left(a-p_{\mathrm{p}}\right)+\left(a-p_{\mathrm{p}}-p_{\mathrm{sm}}+\beta p_{\mathrm{sr}}\right) p_{\mathrm{sm}} .
$$

The retailer's profit function given as follows:

$$
\pi_{\mathrm{r}}=\left(p_{\mathrm{p}}-w\right)\left(a-p_{\mathrm{p}}\right)+\left(a-p_{\mathrm{p}}-p_{\mathrm{sr}}+\beta p_{\mathrm{sm}}\right) p_{\mathrm{sr}} .
$$

As discussed in the work of Wu and Niederhoff [19] on fairness concerns, if the retailer has fairness concerns, it determines its optimal product retail price and extended warranty service price with the aim of maximizing its utility $U_{\mathrm{r}}$, and the manufacturer determines its optimal product wholesale price and extended warranty service price with the aim of maximizing its own profit. When the retailer is fair-minded, its utility function is $U_{\mathrm{r}}=\pi_{\mathrm{r}}^{\mathrm{F}}-\lambda_{0} \pi_{\mathrm{m}}^{\mathrm{F}}$, where $\lambda_{0}=\lambda / 1+\lambda, \lambda(\lambda>0)$ is the intensity of the retailer's fairness concerns. Then, the utility function of the fair-minded retailer can be specified as follows:

$$
\begin{aligned}
U_{\mathrm{r}}^{\mathrm{F}}= & \left(p_{\mathrm{p}}-w\right)\left(a-p_{\mathrm{p}}\right)+\left(a-p_{\mathrm{p}}-p_{\mathrm{sr}}+\beta p_{\mathrm{sm}}\right) p_{\mathrm{sr}} \\
& -\lambda_{0}\left[w\left(a-p_{\mathrm{p}}\right)+\left(a-p_{\mathrm{p}}-p_{\mathrm{sm}}+\beta p_{\mathrm{sr}}\right) p_{\mathrm{sm}}\right] .
\end{aligned}
$$




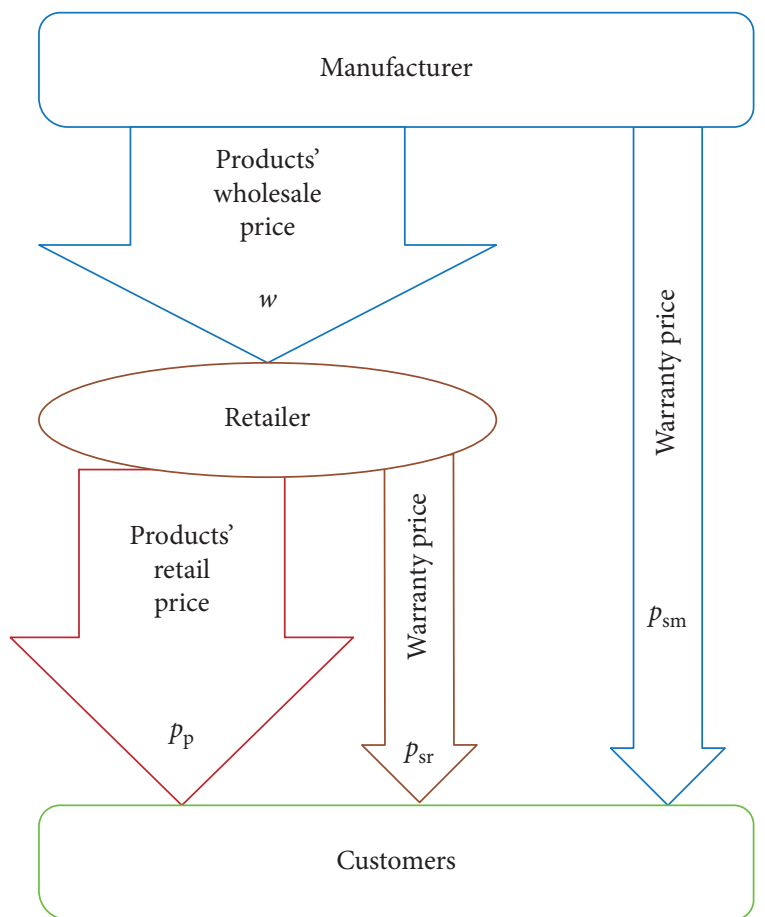

FIgURE 1: Schematic diagram of a product and service supply chain.

\section{Model Solution and Analysis}

3.1. Optimal Decisions of Manufacturer and Retailer without Fairness Concerns. In the partnership between the manufacturer and the retailer, the manufacturer decides the wholesale price $w$ of a specific product, the retailer decides the product sales price $p_{p}$, and then the manufacturer and retailer decide their extended warranty service price $p_{\text {sm }}$ and $p_{\text {sr }}$, respectively. The inverse solution method, which has been widely used by Zhang et al. [28] and Fu et al. [29], is adopted. The optimal profit functions of the manufacturer and retailer are given as follows:

$$
\begin{aligned}
\max _{p_{\mathrm{sm}}} \pi_{\mathrm{m}}\left(p_{\mathrm{sm}}\right)= & w\left(a-p_{\mathrm{p}}\right)+\left(a-p_{\mathrm{p}}-p_{\mathrm{sm}}+\beta p_{\mathrm{sr}}\right) p_{\mathrm{sm}} \\
\max _{p_{\mathrm{sr}}} \pi_{\mathrm{r}}\left(p_{\mathrm{sr}}\right)= & \left(p_{\mathrm{p}}-w\right)\left(a-p_{\mathrm{p}}\right) \\
& +\left(a-p_{\mathrm{p}}-p_{\mathrm{sr}}+\beta p_{\mathrm{sm}}\right) p_{\mathrm{sr}}
\end{aligned}
$$

The second-order derivative of equation (5) with respect to $p_{s m}$ and the second-order derivative of equation (6) with respect to $p_{\mathrm{sr}}$ are

$$
\begin{gathered}
\frac{d^{2} \pi_{\mathrm{m}}\left(p_{\mathrm{sm}}\right)}{d p_{\mathrm{sm}}^{2}}=-2, \\
\frac{d^{2} \pi_{\mathrm{r}}\left(p_{\mathrm{sr}}\right)}{d p_{\mathrm{sr}}^{2}}=-2 .
\end{gathered}
$$

It can be seen that both $\pi_{\mathrm{m}}\left(p_{\mathrm{sm}}\right)$ with respect to $p_{\mathrm{sm}}$ and $\pi_{\mathrm{r}}\left(p_{\mathrm{sr}}\right)$ with respect to $p_{\mathrm{sr}}$ meet the first-order optimality condition. Hence, we have

$$
\begin{gathered}
\frac{d \pi_{\mathrm{m}}\left(p_{\mathrm{sm}}\right)}{d p_{\mathrm{sm}}}=-2 p_{\mathrm{sm}}+a-p_{\mathrm{p}}+\beta p_{\mathrm{sr}}, \\
\frac{d \pi_{\mathrm{r}}\left(p_{\mathrm{sr}}\right)}{d p_{\mathrm{sr}}}=-2 p_{\mathrm{sr}}+a-p_{\mathrm{p}}+\beta p_{\mathrm{sm}} .
\end{gathered}
$$

Based on equations (8) and (9), the optimal extended warranty service price for the manufacturer and the retailer is

$$
\begin{gathered}
p_{\mathrm{sm}}^{*}=\frac{a-p_{\mathrm{p}}}{2-\beta}, \\
p_{\mathrm{sr}}^{*}=\frac{a-p_{\mathrm{p}}}{2-\beta} .
\end{gathered}
$$

Substituting $p_{\mathrm{sm}}^{*}$ and $p_{\mathrm{sr}}^{*}$ into the profit function of the retailer, we can have

$$
\max _{p_{\mathrm{p}}} \pi_{\mathrm{r}}\left(p_{\mathrm{p}}\right)=\frac{\left(a-p_{\mathrm{p}}\right)\left[\left(p_{\mathrm{p}}-w\right) \beta^{2}-4\left(p_{\mathrm{p}}-w\right) \beta+a-4 w+3 p_{\mathrm{p}}\right]}{(\beta-2)^{2}} .
$$

The second-order derivative of equation (11) with respect to $p_{\mathrm{p}}$ is

$$
\frac{d^{2} \pi_{\mathrm{r}}\left(p_{\mathrm{p}}\right)}{d p_{\mathrm{p}}^{2}}=-\frac{2\left(\beta^{2}-4 \beta+3\right)}{(\beta-2)^{2}} .
$$

Since $0<\beta<1$, it follows that $\beta^{2}-4 \beta+3>0$. Then, it is easy to prove $d^{2} \pi_{\mathrm{r}}\left(p_{\mathrm{p}}\right) / d p_{\mathrm{p}}^{2}<0$. Thus, $\pi_{\mathrm{r}}\left(p_{\mathrm{p}}\right)$ with respect to $p_{\mathrm{p}}$ meets the following first-order optimality condition:

$$
\frac{d \pi_{\mathrm{r}}\left(p_{\mathrm{p}}\right)}{d p_{\mathrm{p}}}=\frac{\left(a+w-2 p_{\mathrm{p}}\right) \beta^{2}-4\left(a+w-2 p_{\mathrm{p}}\right) \beta+2 a+4 w-6 p_{\mathrm{p}}}{(\beta-2)^{2}} .
$$

Solving equation (13), we can get the retailer's optimal product retail price as follows:

$$
p_{\mathrm{p}}^{*}=\frac{(a+w) \beta^{2}-4(a+w) \beta+2 a+4 w}{2\left(\beta^{2}-4 \beta+3\right)} .
$$

Likewise, substituting $p_{\mathrm{sm}}^{*}, p_{\mathrm{sr}}^{*}$, and $p_{\mathrm{p}}^{*}$ into the profit function of the manufacturer, we can have

$$
\max _{w} \pi_{\mathrm{m}}(w)=\frac{\left(2 w \beta^{2}-8 w \beta+a+5 w\right)(\beta-2)^{2}(a-w)}{4\left(\beta^{2}-4 \beta+3\right)^{2}} .
$$

The second-order derivative of equation (15) with respect to $w$ is

$$
\frac{d^{2} \pi_{\mathrm{m}}(w)}{d w^{2}}=-\frac{(\beta-2)^{2}\left(\beta^{2}-4 \beta+5 / 2\right)}{\left(\beta^{2}-4 \beta+3\right)^{2}}
$$

Since $0<\beta<1$, it is easy to prove when $0<\beta<$ $2-(\sqrt{6} / 2)$, the second-order condition $d^{2} \pi_{\mathrm{m}}(w) / d w^{2}<0$. In this case, based on the first-order optimality condition, we can get the manufacturer's optimal product wholesale price $w^{*}=\left(a \beta^{2}-4 a \beta+2 a\right) /\left(2 \beta^{2}-8 \beta+5\right)$. Substituting $w^{*}$ into 
the expressions corresponding to $p_{\mathrm{p}}^{*}, p_{\mathrm{sm}}^{*}$, and $p_{\mathrm{sr}}^{*}$, we can obtain $w^{*}=a\left(\beta^{2}-4 \beta+2\right) /\left(2 \beta^{2}-8 \beta+5\right), \quad p_{\mathrm{p}}^{*}=3 a\left(\beta^{2}-\right.$ $4 \beta+2) / 2\left(2 \beta^{2}-8 \beta+5\right)$, and $p_{\mathrm{sm}}^{*}=p_{\mathrm{sr}}^{*}=a(2-\beta) / 2\left(2 \beta^{2}-\right.$ $8 \beta+5)$ From the above analysis, we propose the following proposition.

Proposition 1. Without fairness concerns, both the manufacturer and the retailer can arrive at optimal pricing decisions. The optimal wholesale price and extended warranty service price determined by the manufacturer are

$$
\begin{gathered}
w^{*}=\frac{a\left(\beta^{2}-4 \beta+2\right)}{2 \beta^{2}-8 \beta+5}, \\
p_{\mathrm{sm}}^{*}=\frac{a(2-\beta)}{2\left(2 \beta^{2}-8 \beta+5\right)} .
\end{gathered}
$$

The optimal retail price and extended warranty service price determined by the retailer are

$$
\begin{aligned}
& p_{\mathrm{p}}^{*}=\frac{3 a\left(\beta^{2}-4 \beta+2\right)}{2\left(2 \beta^{2}-8 \beta+5\right)}, \\
& p_{\mathrm{sr}}^{*}=\frac{a(2-\beta)}{2\left(2 \beta^{2}-8 \beta+5\right)} .
\end{aligned}
$$

Proposition 1 shows that when the retailer has no fairness concerns, both the manufacturer and the retailer can make their optimal pricing decisions, and both parties adopt the same extended warranty service pricing strategy. This means that the vertical competition in extended warranty service between the two parties without fairness concerns does not result in differential pricing of extended warranties. Based on the analysis of Proposition 1, this paper explores how the potential market size of a product and the level of competition in extended warranty service on the product affect optimal pricing decisions of both the manufacturer and the retailer. The first-order partial derivatives of $w, p_{\mathrm{p}}$, $p_{\text {sm }}$, and $p_{\text {sr }}$ with respect to $a$ and $\beta$ are calculated, and the following inference is obtained.

Inference 1. If the retailer has no fairness concern, the manufacturer's product wholesale price $w$ and extended warranty service price $p_{\mathrm{sm}}$ and the retailer's product retail price $p_{\mathrm{p}}$ and extended warranty service price $p_{\mathrm{sr}}$ exhibit the following relationships with product market size $a$ and the level $\beta$ of competition in extended warranty service:

(i) $\partial w / \partial a>0, \partial p_{\mathrm{sm}} / \partial a>0 ; \partial w / \partial \beta<0, \partial p_{\mathrm{sm}} / \partial \beta>0$

(ii) $\partial p_{\mathrm{p}} / \partial a>0, \partial p_{\mathrm{sr}} / \partial a>0 ; \partial p_{\mathrm{p}} / \partial \beta<0, \partial p_{\mathrm{sr}} / \partial \beta>0$

Inference 1 indicates that an increase in product market size leads both the manufacturer and the retailer choose to increase the price of their products and extended warranties. As the competition in extended warranty service between the two parties intensifies, they tend to lower the product price as optimal decisions. This price reduction, however, is often accompanied by an increase in the extended warranty service price, meaning that stiffer service competition without fairness concerns contributes little to increasing consumer benefits.

Proposition 2. If the retailer has no fairness concerns, the relationship between the profits of the manufacturer and the retailer and the level of competition in extended warranty service satisfies the following conditions: $\partial \pi_{\mathrm{m}} / \partial \beta>0$, $\partial \pi_{\mathrm{r}} / \partial \beta>0$.

Proof. Substituting $w^{*}, p_{\mathrm{p}}^{*}, p_{\mathrm{sm}}^{*}$, and $p_{\mathrm{sr}}^{*}$ into equation (5), we can have

$$
\pi_{\mathrm{m}}=\frac{a^{2}\left(\beta^{2}-4 \beta+4\right)}{4\left(2 \beta^{2}-8 \beta+5\right)} .
$$

Since $0<\beta<1, \beta^{2}-4 \beta+4>0$ is always true. To ensure that the manufacturer's profit is not less than its retained profit, namely, $\pi_{\mathrm{m}} \geq 0$, the constraint condition $2 \beta^{2}-$ $8 \beta+5>0$, equivalent to $0<\beta<2-(\sqrt{6} / 2)$ must be met. The partial derivative of equation (19) with respect to $\beta$ is

$$
\frac{\partial \pi_{\mathrm{m}}}{\partial \beta}=\frac{3 a^{2}(2-\beta)}{2\left(2 \beta^{2}-8 \beta+5\right)^{2}}
$$

On the premise of satisfying constraint condition $0<\beta<2-(\sqrt{6} / 2), \partial \pi_{\mathrm{m}} / \partial \beta>0$ can be obtained. Similarly, substituting $w^{*}, p_{\mathrm{p}}^{*}, p_{\mathrm{sm}}^{*}$, and $p_{\mathrm{sr}}^{*}$ into equation (6), we can have

$$
\pi_{\mathrm{r}}=\frac{a^{2}(1-\beta)(3-\beta)(\beta-2)^{2}}{4\left(2 \beta^{2}-8 \beta+5\right)^{2}} .
$$

The partial derivative of equation (21) with respect to $\beta$ is

$$
\frac{\partial \pi_{\mathrm{r}}}{\partial \beta}=\frac{a^{2}(2-\beta)\left(4 \beta^{2}-16 \beta+13\right)}{2\left(2 \beta^{2}-8 \beta+5\right)^{3}} .
$$

On the premise of satisfying constraint condition $0<\beta<2-(\sqrt{6} / 2)$, it is easy to get $2 \beta^{2}-8 \beta+5>0$, $(2-\beta)\left(4 \beta^{2}-16 \beta+13\right)>0$. It follows that $\partial \pi_{\mathrm{r}} / \partial \beta>0$. Therefore, Proposition 2 is proven.

From Inference 1 and Proposition 2, it is clear that increasing vertical competition in an extended warranty service between a manufacturer and a retailer which has no fairness concerns leads the manufacturer to lower its product wholesale price and raise its extended warranty service price as the optimal pricing strategy. The same is true of the retailer. The reduction by the manufacturer in product wholesale prices can motivate the retailer to order more products from the manufacturer, and a lower retail price means a higher demand for a specific product, thereby increasing the sales revenue of the two parties. On the other hand, as vertical competition in the extended warranty service intensifies, the optimal decision of both the manufacturer and the retailer is to increase the service price with the aim of increasing the revenue from the service. From the above analysis, we can reach a counterintuitive conclusion: tougher competition in an extended warranty service increases the benefits of both the manufacturer and the 
retailer, instead of harming their interests. However, this inevitably damages the benefits of end users.

3.2. Decisions and Profits of Supply Chain Members with the Retailer Having Fairness Concerns. If a retailer is sensitive to fairness, it determines its retail price and extended warranty service price of a product with the goal of maximizing its utility $U_{\mathrm{r}}$, and the upstream manufacturer still determines its wholesale price and extended warranty service price of the product with the aim of maximizing its own profit. Therefore, despite the retailer's fairness concern, the profit function for the manufacturer remains the same as equation (5) and can be rewritten as follows:

$$
\max _{p_{\mathrm{sm}}} \pi_{\mathrm{m}}^{\mathrm{F}}\left(p_{\mathrm{sm}}\right)=w\left(a-p_{\mathrm{p}}\right)+\left(a-p_{\mathrm{p}}-p_{\mathrm{sm}}+\beta p_{\mathrm{sr}}\right) p_{\mathrm{sm}} .
$$

As discussed in $[19,23]$, the utility function of the fairminded retailer is

$$
U_{\mathrm{r}}=\pi_{\mathrm{r}}^{\mathrm{F}}-\lambda_{0} \pi_{\mathrm{m}}^{\mathrm{F}}
$$

where $\lambda_{0}=\lambda /(1+\lambda) \quad(\lambda$ denotes the retailer's fairness preference). Referring to equations (24) and (6), we can get the following utility function of the fair-minded retailer:

$$
\begin{aligned}
\max _{p_{\mathrm{sr}}} U_{\mathrm{r}}^{\mathrm{F}}\left(p_{\mathrm{sr}}\right)= & \left(p_{\mathrm{p}}-w\right)\left(a-p_{\mathrm{p}}\right)+\left(a-p_{\mathrm{p}}-p_{\mathrm{sr}}+\beta p_{\mathrm{sm}}\right) p_{\mathrm{sr}} \\
& -\lambda_{0}\left[w\left(a-p_{\mathrm{p}}\right)+\left(a-p_{\mathrm{p}}-p_{\mathrm{sm}}+\beta p_{\mathrm{sr}}\right) p_{\mathrm{sm}}\right] .
\end{aligned}
$$

Following the same logic of analysing optimal pricing decisions without fairness concerns, calculate the first-order and second-order derivatives of equation (23) with respect to $p_{\text {sm }}$ and calculate the first-order and second-order derivatives of equation (25) with respect to $p_{\mathrm{sr}}$. Combining the two first-order optimality conditions, we can derive the optimal extended warranty service price:

$$
\begin{aligned}
& p_{\mathrm{sr}}^{F *}=\frac{\left[2-\left(\lambda_{0}-1\right) \beta\right]\left(a-p_{\mathrm{p}}\right)}{4+\left(\lambda_{0}-1\right) \beta^{2}}, \\
& p_{\mathrm{sm}}^{F *}=\frac{(2+\beta)\left(a-p_{\mathrm{p}}\right)}{4+\left(\lambda_{0}-1\right) \beta^{2}} .
\end{aligned}
$$

Substituting $p_{\mathrm{sr}}^{\mathrm{F} *}$ and $p_{\mathrm{sm}}^{\mathrm{F} *}$ into equation (25), we can have

$$
\begin{aligned}
\max _{p_{\mathrm{p}}} U_{\mathrm{r}}^{\mathrm{F}}\left(p_{\mathrm{p}}\right)= & \left(p_{\mathrm{p}}-w\right)\left(a-p_{\mathrm{p}}\right)+\left(a-p_{\mathrm{p}}-p_{\mathrm{sr}}^{F *}+\beta p_{\mathrm{sm}}^{F *}\right) p_{\mathrm{sr}}^{F *} \\
& -\lambda_{0}\left[w\left(a-p_{\mathrm{p}}\right)+\left(a-p_{\mathrm{p}}-p_{\mathrm{sm}}^{F *}+\beta p_{\mathrm{sr}}^{F *}\right) p_{\mathrm{sm}}^{F *}\right] .
\end{aligned}
$$

Following the same logic of solving $p_{\mathrm{p}}^{*}$ to determine the retailer's optimal retail price for the objective function (27), we can have

$$
p_{\mathrm{p}}^{F *}=\frac{\left(a+\lambda_{0} w+w\right)\left(\lambda_{0}-1\right)^{2} \beta^{4}+2 a \lambda_{0}\left(\lambda_{0}-1\right) \beta^{3}+\left[(2 a+8 w) \lambda_{0}^{2}+6 a \lambda_{0}-10 a-8 w\right] \beta^{2}+8 a\left(\lambda_{0}-1\right) \beta+8\left(\lambda_{0}+1\right)(a+2 w)}{2\left(\lambda_{0}-1\right)^{2} \beta^{4}+2 \lambda_{0}\left(\lambda_{0}-1\right) \beta^{3}+2\left(\lambda_{0}^{2}+7 \lambda_{0}+4\right) \beta^{2}+8\left(\lambda_{0}-1\right) \beta+8 \lambda_{0}+24} .
$$
have

Substituting $p_{\mathrm{sr}}^{F *}, p_{\mathrm{sm}}^{F *}$, and $p_{\mathrm{p}}^{F *}$ into equation (23), we can

$$
\max _{w} \pi_{\mathrm{m}}^{\mathrm{F}}(w)=w\left(a-p_{\mathrm{p}}^{F *}\right)+\left(a-p_{\mathrm{p}}^{F *}-p_{\mathrm{sm}}^{F *}+\beta p_{\mathrm{sr}}^{F *}\right) p_{\mathrm{sm}}^{F *} .
$$

Following the same logic of solving $w^{*}$ to determine the manufacturer's optimal wholesale price for the objective function (29), we can have

$$
w^{\mathrm{F} *}=\frac{a\left[\left(\lambda_{0}^{2}-2 \lambda_{0}+1\right) \beta^{4}+\left(\lambda_{0}^{2}-\lambda_{0}\right) \beta^{3}+\left(\lambda_{0}^{2}+6 \lambda_{0}-10\right) \beta^{2}-8 \beta+8\right]}{\left(\lambda_{0}+1\right)\left[\left(2 \lambda_{0}^{2}-4 \lambda_{0}+2\right) \beta^{4}+\left(2 \lambda_{0}^{2}-2 \lambda_{0}\right) \beta^{3}+\left(2 \lambda_{0}^{2}+13 \lambda_{0}-19\right) \beta^{2}+\left(4 \lambda_{0}-12\right) \beta+4 \lambda_{0}+20\right]} .
$$


Substituting $w^{F *}$ into the equations corresponding to $p_{\mathrm{sr}}^{F *}, p_{\mathrm{sm}}^{F *}$, and $p_{\mathrm{p}}^{F *}$, we can obtain the retailer's and manufacturer's optimal prices:

$$
\begin{aligned}
& p_{\mathrm{p}}^{F *}=\frac{a\left[3\left(\lambda_{0}-1\right)^{2} \beta^{4}+\left(4 \lambda_{0}^{2}-4 \lambda_{0}\right) \beta^{3}+\left(4 \lambda_{0}^{2}+18 \lambda_{0}-30\right) \beta^{2}+\left(8 \lambda_{0}-24\right) \beta+8 \lambda_{0}+24\right]}{4\left(\lambda_{0}-1\right)^{2} \beta^{4}+\left(4 \lambda_{0}^{2}-4 \lambda_{0}\right) \beta^{3}+\left(4 \lambda_{0}^{2}+26 \lambda_{0}-38\right) \beta^{2}+\left(8 \lambda_{0}-24\right) \beta+8 \lambda_{0}+40}, \\
& p_{\mathrm{sm}}^{F *}=\frac{a(\beta+2)\left[4+\beta^{2}\left(\lambda_{0}-1\right)\right]}{4\left(\lambda_{0}-1\right)^{2} \beta^{4}+\left(4 \lambda_{0}^{2}-4 \lambda_{0}\right) \beta^{3}+\left(4 \lambda_{0}^{2}+26 \lambda_{0}-38\right) \beta^{2}+\left(8 \lambda_{0}-24\right) \beta+8 \lambda_{0}+40}, \\
& p_{\mathrm{sr}}^{F *}=\frac{a\left[2-\beta\left(\lambda_{0}-1\right)\right]\left[4+\beta^{2}\left(\lambda_{0}-1\right)\right]}{4\left(\lambda_{0}-1\right)^{2} \beta^{4}+\left(4 \lambda_{0}^{2}-4 \lambda_{0}\right) \beta^{3}+\left(4 \lambda_{0}^{2}+26 \lambda_{0}-38\right) \beta^{2}+\left(8 \lambda_{0}-24\right) \beta+8 \lambda_{0}+40} .
\end{aligned}
$$

Based on the above analysis and the analysis of Proposition 1 , we propose the following proposition.
Proposition 3. If the retailer is fair-minded, both the manufacturer and the retailer can arrive at optimal pricing decisions. The optimal wholesale price and extended warranty service price determined by the manufacturer are

$$
\begin{aligned}
& w^{F *}=\frac{a\left[\left(\lambda_{0}^{2}-2 \lambda_{0}+1\right) \beta^{4}+\left(\lambda_{0}^{2}-\lambda_{0}\right) \beta^{3}+\left(\lambda_{0}^{2}+6 \lambda_{0}-10\right) \beta^{2}-8 \beta+8\right]}{\left(\lambda_{0}+1\right)\left(2 \lambda_{0}^{2}-4 \lambda_{0}+2\right) \beta^{4}+\left(2 \lambda_{0}^{2}-2 \lambda_{0}\right) \beta^{3}+\left(2 \lambda_{0}^{2}+13 \lambda_{0}-19\right) \beta^{2}+\left(4 \lambda_{0}-12\right) \beta+4 \lambda_{0}+20}, \\
& p_{\mathrm{sm}}^{F *}=\frac{a(\beta+2)\left[4+\beta^{2}\left(\lambda_{0}-1\right)\right]}{4\left(\lambda_{0}-1\right)^{2} \beta^{4}+\left(4 \lambda_{0}^{2}-4 \lambda_{0}\right) \beta^{3}+\left(4 \lambda_{0}^{2}+26 \lambda_{0}-38\right) \beta^{2}+\left(8 \lambda_{0}-24\right) \beta+8 \lambda_{0}+40} .
\end{aligned}
$$

The optimal product retail price and extended warranty service price determined by the retailer are

$$
\begin{aligned}
& p_{\mathrm{p}}^{F *}=\frac{a\left[3\left(\lambda_{0}-1\right)^{2} \beta^{4}+\left(4 \lambda_{0}^{2}-4 \lambda_{0}\right) \beta^{3}+\left(4 \lambda_{0}^{2}+18 \lambda_{0}-30\right) \beta^{2}+\left(8 \lambda_{0}-24\right) \beta+8 \lambda_{0}+24\right]}{4\left(\lambda_{0}-1\right)^{2} \beta^{4}+\left(4 \lambda_{0}^{2}-4 \lambda_{0}\right) \beta^{3}+\left(4 \lambda_{0}^{2}+26 \lambda_{0}-38\right) \beta^{2}+\left(8 \lambda_{0}-24\right) \beta+8 \lambda_{0}+40}, \\
& p_{\mathrm{sr}}^{F *}=\frac{a\left[2-\beta\left(\lambda_{0}-1\right)\right]\left[4+\beta^{2}\left(\lambda_{0}-1\right)\right]}{4\left(\lambda_{0}-1\right)^{2} \beta^{4}+\left(4 \lambda_{0}^{2}-4 \lambda_{0}\right) \beta^{3}+\left(4 \lambda_{0}^{2}+26 \lambda_{0}-38\right) \beta^{2}+\left(8 \lambda_{0}-24\right) \beta+8 \lambda_{0}+40} .
\end{aligned}
$$

Proposition 3 shows that when the retailer has fairness concerns, both the manufacturer and the retailer can make optimal pricing decisions and they adopt different extended warranty service pricing strategies. This indicates that the fairness concerns of the retailer which experiences vertical competition in an extended warranty service with the manufacturer lead to differential pricing of the service.

Based on the analysis of Proposition 3, this paper investigates how the potential market size of a product, the level of competition in extended warranty service on the product, and the retailer's fairness preference influence the optimal pricing decisions of both the manufacturer and the retailer. The first-order partial derivatives of $w^{\mathrm{F}}, p_{\mathrm{p}}^{\mathrm{F}}, p_{\mathrm{sm}}^{\mathrm{F}}$, and $p_{\mathrm{sr}}^{\mathrm{F}}$ with respect to $a, \beta$, and $\lambda$ are calculated, and the following inference is obtained.
Inference 2. If the retailer has fairness concerns, the manufacturer's optimal product wholesale price and extended warranty service price and the retailer's optimal product retail price and extended warranty service price exhibit the following relationships with product market size $a$ and the level $\beta$ of competition in extended warranty service:

(i) $\partial w^{\mathrm{F}} / a>0, \partial w^{\mathrm{F}} / \beta<0, \partial w^{\mathrm{F}} / \lambda<0$

(ii) $\partial p_{\mathrm{p}}^{\mathrm{F}} / a>0, \partial p_{\mathrm{p}}^{\mathrm{F}} / \beta<0, \partial p_{\mathrm{p}}^{\mathrm{F}} / \lambda>0$

(iii) $\partial p_{\mathrm{sr}}^{\mathrm{F}} / a>0, \partial p_{\mathrm{sr}}^{\mathrm{F}} / \beta>0, \partial p_{\mathrm{sr}}^{\mathrm{F}} / \lambda<0$

(iv) $\partial p_{\mathrm{sm}}^{\mathrm{F}} / a>0, \partial p_{\mathrm{sm}}^{\mathrm{F}} / \beta>0, \partial p_{\mathrm{sm}}^{\mathrm{F}} / \lambda<0$

Proof

(i) The partial derivatives of $w^{\mathrm{F}}$ with respect to product market size $a$ and the level $\beta$ of competition in 
extended warranty service are obtained. It is easy to prove $\partial w^{\mathrm{F}} / a>0, \partial w^{\mathrm{F}} / \beta<0$. To determine the sign of $\partial w^{\mathrm{F}} / \lambda$, the partial derivative of $w^{\mathrm{F}}$ with respect to $\lambda_{0}$ is calculated as follows:

$$
\frac{\partial w^{\mathrm{F}}}{\lambda_{0}}=\frac{(\beta+2) a l}{m^{2}},
$$

where $l=2\left(\lambda_{0}-1\right)^{2} \beta^{4}+\left(9 \lambda_{0}^{2}-17 \lambda_{0}+8\right) \beta^{3}+6\left(\lambda_{0}^{2}-\right.$ $\left.\lambda_{0}\right) \beta^{2}+\left(4 \lambda_{0}^{2}+24 \lambda_{0}-32\right) \beta-32$ and $m=2\left(\lambda_{0}-1\right)^{2}$ $\beta^{4}+2\left(\lambda_{0}^{2}-\lambda_{0}\right) \beta^{3}+\left(2 \lambda_{0}^{2}+13 \lambda_{0}-19\right) \beta^{2}+2\left(2 \lambda_{0}-6\right)$ $\beta+20$. Since $0<\beta<1$, it is easy to prove $l<0$. Hence, $\partial w^{\mathrm{F}} / \lambda_{0}=(\beta+2) a l / m^{2}<0$. Then, because $\lambda_{0}=\lambda /(\lambda$ $+1)$, it follows that $\partial w^{\mathrm{F}} / \lambda<0$.

(ii) Solving the partial derivative of retail price $p_{p}^{F}$ with respect to product market size $a$, we can have $\partial p_{\mathrm{p}}^{\mathrm{F}} / a>0$. Solving the partial derivative of retail price $p_{\mathrm{p}}^{\mathrm{F}}$ with respect to the level $\beta$ of competition in extended warranty service, we can have

$$
\frac{\partial p_{\mathrm{p}}^{\mathrm{F}}}{\beta}=-\frac{j a}{4 k^{2}},
$$

where $k=\left(\lambda_{0}-1\right)^{2} \beta^{4}+\left(\lambda_{0}^{2}-\lambda_{0}\right) \beta^{3}+\left(\lambda_{0}^{2}+(13 / 2) \lambda_{0}-\right.$ $(19 / 2)) \beta^{2}+\left(2 \lambda_{0}-6\right) \beta+2 \lambda_{0}+10$ and $j=\left(\left(\lambda_{0}-1\right) \beta^{2}\right.$ $+4)\left(\lambda_{0}\left(\lambda_{0}-1\right)^{2} \beta^{4}+\left(2 \lambda_{0}^{3}-5 \lambda_{0}^{2}+3\right) \beta^{3}+\left(-6 \lambda_{0}^{2}-12 \lambda_{0}\right.\right.$ $\left.+18) \beta^{2}+\left(-2 \lambda_{0}+36\right) \beta-8 \lambda_{0}+24\right)$. Since $0<\beta<1$, $\lambda_{0}=\lambda /(\lambda+1)$, it is easy to prove $j>0$. Hence, $\partial p_{\mathrm{p}}^{\mathrm{F}} / \beta=-j a / 4 k^{2}<0$. To determine the sign of $\partial p_{\mathrm{p}}^{\mathrm{F}} / \lambda$, the partial derivative of $p_{\mathrm{p}}^{\mathrm{F}}$ with respect to $\lambda_{0}$ is calculated as follows:

$$
\frac{\partial p_{\mathrm{p}}^{\mathrm{F}}}{\lambda_{0}}=-\frac{\phi(\beta+2) a}{4 \varphi^{2}}
$$

where $\varphi=\left(\lambda_{0}-1\right)^{2} \beta^{4}+\left(\lambda_{0}^{2}-\lambda_{0}\right) \beta^{3}+\left(\lambda_{0}^{2}+(13 / 2)\right.$ $\left.\lambda_{0}-(19 / 2)\right) \beta^{2}+\left(2 \lambda_{0}-1\right) \beta+2 \lambda_{0}+10$ and $\phi=$ $\left(\lambda_{0}-1\right) \beta^{4}-\left(3 / 2 \lambda_{0}+5 / 2\right) \beta^{3}-\left(3 \lambda_{0}+1\right) \beta^{2}-2 \beta-4$. Since $0<\beta<1$ and $\lambda_{0}=\lambda /(\lambda+1)$, it is easy to prove $\phi<0$. Hence, $\partial p_{\mathrm{p}}^{\mathrm{F}} / \lambda>0$.

(iii) Solving the partial derivative of the retailer's optimal extended warranty service price $p_{\text {sr }}^{\mathrm{F}}$ with respect to product market size $a$, we can have $\partial p_{\mathrm{sr}}^{\mathrm{F}} / a>0$. Following the proof logic in (ii), we can derive $\partial p_{\mathrm{sr}}^{\mathrm{F}} / \beta>0, \partial p_{\mathrm{sr}}^{\mathrm{F}} / \lambda<0$.

(iv) Likewise, we can derive $\partial p_{\mathrm{sm}}^{\mathrm{F}} / a>0, \partial p_{\mathrm{sm}}^{\mathrm{F}} / \beta>0$, $\partial p_{\mathrm{sm}}^{\mathrm{F}} / \lambda<0$.

The results from the analysis of Inference 1 and Inference 2 show that when the retailer has fairness concerns, market size and the level of vertical competition in extended warranty service influence the optimal pricing decisions of the manufacturer in a way similar to what they do for the retailer. This indicates that the retailer's fairness concerns do not change the direction in which market size and vertical competition in extended warranty service influence optimal pricing decisions in the product and service supply chain. Further analysis reveals that in the face of increasing intensity of the retailer's fairness concerns, the manufacturer can offset the concerns and indirectly receive compensation by lowering its product wholesale price and the retailer can improve its profits by raising the retail price. In addition, both the manufacturer and the retailer can decrease the price of extended warranties to attract consumers to purchase the service, thereby increasing their revenue.

The findings from the analysis of Proposition 3 and Inference 2 suggest that the retailer's fairness concerns can lead to differential pricing of extended warranties, though they do not change the direction in which market size and vertical competition in extended warranty service affect the optimal pricing decisions of the retailer and manufacturer. It can be seen that the manufacturer and retailer may determine different extended warranty service price if the retailer is fairminded. Then, how does the retailer's fairness concern affect this price difference? And is this price difference connected with the level of vertical competition in extended warranty service in the context of the retailer's fairness concerns? The following proposition will answer these questions.

\section{Proposition 4}

(i) When the retailer has fairness concerns, the difference in extended warranty service price between the retailer and manufacturer meets $p_{\mathrm{sm}}^{F *}>p_{\mathrm{sr}}^{F *}$.

(ii) The relationship between the difference $p_{\mathrm{sm}}^{F *}-p_{\mathrm{sr}}^{F *}$ in extended warranty service price and the level $\beta$ of competition in extended warranty service meets $\partial\left(p_{\mathrm{sm}}^{F *}-p_{\mathrm{sr}}^{F *}\right) / \partial \beta>0$.

(iii) The relationship between the difference $p_{\mathrm{sm}}^{F *}-p_{\mathrm{sr}}^{F *}$ in extended warranty service price and the intensity of the retailer's fairness concerns is as follows: if the intensity of the fairness concerns meets $0<\lambda$ $<(1-\tau) / \tau$, then $\partial\left(p_{\mathrm{sm}}^{F *}-p_{\mathrm{sr}}^{F *}\right) / \partial \lambda<0$; if the concern intensity meets $\lambda>(1-\tau) / \tau$, then $\partial\left(p_{\mathrm{sm}}^{F *}-p_{\mathrm{sr}}^{F *}\right) / \partial \lambda>0$, where $\tau=\left(2 \beta^{3}-8 \beta^{2}+2\right.$ $\left.\sqrt{-2 \beta^{4}+8 \beta^{3}-3 \beta^{2}-8 \beta+5}+5 \beta\right)(\beta+2) /\left(2 \beta^{3}-4 \beta\right.$ $2+\beta+2) \beta$.

Proof

(i) Referring to the expressions of $p_{\mathrm{sm}}^{F *}$ and $p_{\mathrm{sr}}^{F *}$ in Proposition 3, which share the same denominator, we can tell if $p_{\mathrm{sm}}^{F *}$ is larger or smaller than $p_{\mathrm{sr}}^{F *}$ only by comparing $(\beta+2)$ against $\left[2-\beta\left(\lambda_{0}-1\right)\right]$. Since $0<\beta<1, p_{\mathrm{sm}}^{F *}>p_{\mathrm{sr}}^{F *}$ is proven.

(ii) In the discussion on the relationship between the difference in extended warranty service price and the level of competition in extended warranty service, the price difference is expressed as follows: 


$$
p_{\mathrm{sm}}^{F *}-p_{\mathrm{sr}}^{F *}=\frac{a \lambda_{0} \beta\left[4+\beta^{2}\left(\lambda_{0}-1\right)\right]}{4\left(\lambda_{0}-1\right)^{2} \beta^{4}+\left(4 \lambda_{0}^{2}-4 \lambda_{0}\right) \beta^{3}+\left(4 \lambda_{0}^{2}+26 \lambda_{0}-38\right) \beta^{2}+\left(8 \lambda_{0}-24\right) \beta+8 \lambda_{0}+40}
$$

The partial derivative of $p_{\mathrm{sm}}^{F *}-p_{\mathrm{sr}}^{F *}$ with respect to $\beta$ is

$$
\frac{\partial\left(p_{\mathrm{sm}}^{F *}-p_{\mathrm{sr}}^{F *}\right)}{\partial \beta}=\frac{-a \lambda_{0} \gamma}{4 \eta^{2}}
$$

where $\gamma=\left(\lambda_{0}-1\right)^{3} \beta^{6}-\left(\lambda_{0}^{3}-(13 / 2) \lambda_{0}^{2}+8 \lambda_{0}-(5 /\right.$ 2)) $\beta^{4}+\left(4 \lambda_{0}^{2}+8 \lambda_{0}-12\right) \beta^{3}-\left(2 \lambda_{0}^{2}-2 \lambda_{0}+8\right) \beta^{2}-8 \lambda_{0}$ -40 and $\eta=\left(\beta^{4}+\beta^{3}+\beta^{2}\right) \lambda_{0}^{2}-\left(2 \beta^{4}+\beta^{3}-(13 / 2) \beta^{2}\right.$ $-2 \beta-2) \lambda_{0}+\beta^{4}-(19 / 2) \beta^{2}-6 \beta+10$. Since $0<\beta$ $<1$ and $0<\lambda_{0}<1$, we have $\gamma<0$. Hence, $\partial\left(p_{\mathrm{sm}}^{F *}-p_{\mathrm{sr}}^{F *}\right) / \partial \beta=-a \lambda_{0} \gamma / 4 \eta^{2}>0$.

(iii) The partial derivative of $p_{\mathrm{sm}}^{F *}-p_{\mathrm{sr}}^{F *} \mathrm{p}_{\mathrm{sm}}^{F *}-\mathrm{p}_{\mathrm{sr}}^{F *}$ with respect to $\lambda_{0}$ is

$$
\frac{\partial\left(p_{\mathrm{sm}}^{F *}-p_{\mathrm{sr}}^{F *}\right)}{\partial \lambda_{0}}=-\frac{a \beta(\beta+2) \nu}{4 \eta^{2}}
$$

where $v=\left(\lambda_{0}-1\right)^{2} \beta^{5}-2\left(\lambda_{0}-1\right) \beta^{4}+\left(1 / 2 \lambda_{0}^{2}+11 \lambda_{0}-(19 /\right.$ 2)) $\beta^{3}+\left(\lambda_{0}^{2}-10 \lambda_{0}+13\right) \beta^{2}+22 \beta-20$. Let $\tau=\left(2 \beta^{3}-8 \beta^{2}+\right.$ $\left.2 \sqrt{-2 \beta^{4}+8 \beta^{3}-3 \beta^{2}-8 \beta+5}+5 \beta\right)(\beta+2) /\left(2 \beta^{3}-4 \beta^{2}+\beta+\right.$ 2) $\beta$. If $0<\lambda_{0}<\tau$, namely, $0<\lambda<(1-\tau) / \tau$, we have $v>0$. Hence, $\partial\left(p_{\mathrm{sm}}^{F *}-p_{\mathrm{sr}}^{F *}\right) / \partial \lambda=-a \beta(\beta+2) \nu / 4 \eta^{2}<0$. If $\tau<\lambda_{0}<1$, namely, $\quad 0<(1-\tau) / \tau<\lambda$, we have $v<0$. Hence, $\partial\left(p_{\mathrm{sm}}^{F *}-p_{\mathrm{sr}}^{F *}\right) / \partial \lambda=-a \beta(\beta+2) \nu / 4 \eta^{2}>0$. Therefore, Proposition 4 (iii) is proven.

Proposition 4(i) shows that when the retailer has fairness concerns, the manufacturer tends to develop a differential pricing strategy in which it offers a specific extended warranty service at a price above that of the retailer, thereby shifting some of the consumer demand for the service to the retailer to compensate the retailer. Proposition 4(ii) implies that generally, the higher the level of vertical competition in an extended warranty service between the manufacturer and retailer, the greater the price difference in the extended warranty service provided by the two parties. This is mainly because increasing competition between the two parties means a greater negotiation power of the retailer, which forces the manufacturer to surrender part of its profits to the retailer by increasing its own extended warranty service price. From Proposition 4(iii), it can be seen that the intensity of the retailer's fairness concerns directly affects the differential pricing strategy for an extended warranty service subjected to vertical competition with the manufacturer. If the intensity of the retailer's fairness concerns is less than a certain threshold $(0<\lambda<(1-\tau) / \tau)$, they will not draw considerable attention from the manufacturer. Instead, an increase in the intensity of the fairness concerns will narrow the price gap in the extended warranty service between the manufacturer and retailer. This means that a higher intensity of the retailer's fairness concerns will reduce its own revenue from the extended warranty service. If the intensity of retailer's fairness concerns is greater than the threshold $(\lambda>(1-\tau) / \tau>0)$, increasing intensity of the retailer's fairness concerns implies a greater difference in extended warranty service price between the manufacturer and retailer, and the greater the price difference, the more likely the retailer is to improve its revenue from the extended warranty service.

Proposition 5. When the retailer has fairness concerns,

(i) The relationship between the manufacturer's profit function and the level of vertical competition in extended warranty service as well as the intensity of the retailer's fairness concerns meets $\partial \pi_{\mathrm{m}}^{\mathrm{F}} / \partial \beta>0$, $\partial \pi_{\mathrm{m}}^{\mathrm{F}} / \partial \lambda<0$.

(ii) The relationship between the retailer's utility function and the level of vertical competition in extended warranty service as well as the intensity of the retailer's fairness concerns is as follows: if the intensity of the fairness concerns meets $0<\lambda<\omega /(1-\omega)$, then $\partial U_{\mathrm{r}}^{\mathrm{F}} / \partial \beta<0, \quad \partial U_{\mathrm{r}}^{\mathrm{F}} / \partial \lambda>0$; if the concern intensity meets $\omega /(1-\omega)<\lambda$, then $\partial U_{\mathrm{r}}^{\mathrm{F}} / \partial \beta>0, \partial U_{\mathrm{r}}^{\mathrm{F}} / \partial \lambda<0$, where $\omega=\left(2 \beta^{4}+\beta^{3}-(13 / 2) \beta^{2}-2 \beta-2\right)+\sqrt{\Delta} / 2$ $\left(\beta^{4}+\beta^{3}+\beta^{2}\right)$ and $\Delta=9 \beta^{6}+41 \beta^{5}+209 / 4 \beta^{4}+6 \beta^{3}-$ $10 \beta^{2}+8 \beta+4$.

Proof

(i) Substituting optimal product prices $w^{F *}$ and $p_{\mathrm{sr}}^{F *}$ and optimal extended warranty service prices $p_{\mathrm{sm}}^{F *}$ and $p_{\mathrm{p}}^{F *}$ into the manufacturer's profit function (23), we can have

$$
\pi_{\mathrm{m}}^{\mathrm{F}}=\frac{a^{2}\left[\beta^{4} \lambda_{0}^{2}+\left(8 \beta^{2}-2 \beta^{4}\right) \lambda_{0}+\beta^{4}-8 \beta^{2}+16\right]}{4\left[2\left(\beta^{4}+\beta^{3}+\beta^{2}\right) \lambda_{0}^{2}+\left(13 \beta^{2}-4 \beta^{4}-2 \beta^{3}\right) \lambda_{0}+2 \beta^{4}-19 \beta^{2}+20\right]\left(1+\lambda_{0}\right)} .
$$


The first-order partial derivative of equation (40) with respect to the level $\beta$ of vertical competition in extended warranty service is

$$
\frac{\partial \pi_{\mathrm{m}}^{\mathrm{F}}}{\partial \beta}=\frac{a^{2}\left[4+\left(\lambda_{0}-1\right) \beta^{2}\right]}{8\left(1+\lambda_{0}\right) \eta^{2} \Upsilon}
$$

where $\Upsilon=\left[\left(\beta^{4}+2 \beta^{3}\right) \lambda_{0}^{3}-\left(2 \beta^{4}+5 \beta^{3}+6 \beta^{2}\right) \lambda_{0}^{2}+\left(\beta^{4}\right.\right.$ $\left.\left.-12 \beta^{2}-20 \beta-8\right) \lambda_{0}+3 \beta^{3}+18 \beta^{2}+36 \beta+24\right]$. Since $0<$ $\beta<1, \quad 0<\lambda_{0}<1$, it is easy to prove $0<\left(1+\lambda_{0}\right)$, $0<4+\left(\lambda_{0}-1\right) \beta^{2}, \Upsilon>0$. Therefore, $\partial \pi_{\mathrm{m}}^{\mathrm{F}} / \partial \beta>0$ is proven.

Likewise, the first-order partial derivative of equation (40) with respect to $\lambda_{0}$ is

$$
\frac{\partial \pi_{\mathrm{m}}^{\mathrm{F}}}{\partial \lambda_{0}}=-\frac{a^{2}\left[\left(\lambda_{0}-1\right) \beta^{2}+4\right] \psi}{8\left(\lambda_{0}+1\right)^{2} \eta^{2}}
$$

where $\psi=\left(\beta^{6}+\beta^{5}+\beta^{4}\right) \lambda_{0}^{3}-\left(3 \beta^{6}+3 \beta^{5}-9 \beta^{4}-12\right.$ $\left.\beta^{3}-12 \beta^{2}\right) \lambda_{0}^{2}+\left(3 \beta^{6}+\beta^{5}-20 \beta^{4}+44 \beta^{2}+16 \beta+16\right)$ $\lambda_{0}-\beta^{6}+\beta^{5}+18 \beta^{4}+12 \beta^{3}-44 \beta^{2}-16 \beta+48$. Since $0<\beta<1,0<\lambda_{0}<1$, it is easy to prove that $0<\psi$ is always true. Hence, $\partial \pi_{\mathrm{m}}^{\mathrm{F}} / \partial \lambda_{0}<0$. Then, since $\lambda_{0}=\lambda /(\lambda+1), \partial \pi_{\mathrm{m}}^{\mathrm{F}} / \partial \lambda<0$ is proven.

(ii) Substituting $w^{F *}, p_{\mathrm{sr}}^{F *}, p_{\mathrm{sm}}^{F *}$, and $p_{\mathrm{p}}^{F *}$ into the retailer's utility function (25), we can have

$$
U_{\mathrm{r}}^{\mathrm{F}}=\frac{a^{2}\left[\left(\lambda_{0}-1\right) \beta^{2}+4\right]^{2}\left[\left(\lambda_{0}-1\right)^{2} \beta^{4}+\left(\lambda_{0}^{2}-\lambda_{0}\right) \beta^{3}+\left(\lambda_{0}^{2}+7 \lambda_{0}-9\right) \beta^{2}+\left(4 \lambda_{0}-4\right) \beta+4 \lambda_{0}+12\right]}{16 \eta^{2}},
$$

where $\eta=\left(\beta^{4}+\beta^{3}+\beta^{2}\right) \lambda_{0}^{2}-\left(2 \beta^{4}+\beta^{3}-(13 / 2) \beta^{2}-2 \beta-2\right)$ $\lambda_{0}+\beta^{4}-(19 / 2) \beta^{2}-6 \beta+10$.

To analyse the relationship between the retailer's utility function and the intensity of its fairness concerns, the firstorder partial derivative of equation (43) with respect to $\lambda_{0}$ is calculated as follows:

$$
\frac{\partial U_{\mathrm{r}}^{\mathrm{F}}}{\partial \lambda_{0}}=\frac{a^{2}(\beta+2)\left[\left(\lambda_{0}-1\right) \beta^{2}+4\right] \sigma}{16 \eta^{3}},
$$

where $\quad \sigma=\left(\beta^{8}-\beta^{7}-5 \beta^{6}-6 \beta^{5}-4 \beta^{4}\right) \lambda_{0}^{3}-\left(3 \beta^{8}+2 \beta^{7}\right.$ $\left.-(17 / 2) \beta^{6}+(25 / 2) \beta^{5}+37 \beta^{4}+30 \beta^{3}+20 \beta^{2}\right) \lambda_{0}^{2}+\left(3 \beta^{8}+7 \beta^{8}\right.$ $\left.-8 \beta^{6}-15 \beta^{5}+4 \beta^{4}-46 \beta^{3}-76 \beta^{2}-24 \beta-16\right) \lambda_{0}-\beta^{8}-4 \beta^{7}+$ $(9 / 2) \beta^{6}+(15 / 2) \beta^{5}+37 \beta^{4}-56 \beta^{2}-24 \beta-16$. Since $0<\beta<$ $1,0<\lambda_{0}<1$, it is easy to prove that $\sigma<0$ is always true. It follows that the numerator in equation (44) is negative. To determine the sign of $\partial U_{\mathrm{r}}^{\mathrm{F}} / \partial \lambda_{0}$, only the sign of $\eta$ needs to be considered. Since the root on the left side of equation $\eta=0$ is

$$
\frac{\left(2 \beta^{4}+\beta^{3}-(13 / 2) \beta^{2}-2 \beta-2\right)-\sqrt{\Delta}}{2\left(\beta^{4}+\beta^{3}+\beta^{2}\right)}<0,
$$

where $\Delta=9 \beta^{6}+41 \beta^{5}+(209 / 4) \beta^{4}+6 \beta^{3}-10 \beta^{2}+8 \beta+4>0$, we assume that the root on the right side is $\omega=\left(2 \beta^{4}+\beta^{3}-(13 / 2) \beta^{2}-2 \beta-2\right)+\sqrt{\Delta} / 2\left(\beta^{4}+\beta^{3}+\beta^{2}\right)$. It follows that if $0<\lambda_{0}<\omega$, then $\eta<0$. It is easy to prove $\partial U_{\mathrm{r}}^{\mathrm{F}} / \partial \lambda_{0}>0$. Furthermore, since $\lambda_{0}=\lambda /(\lambda+1)$, equivalent to $\partial U_{\mathrm{r}}^{\mathrm{F}} / \partial \lambda>0$, we have $0<\lambda<\omega /(1-\omega)$. Likewise, when $\omega<\lambda_{0}$, equivalent to $\omega /(1-\omega)<\lambda$, we have $\partial U_{\mathrm{r}}^{\mathrm{F}} / \partial \lambda<0$.

Following the logic of analysing the relationship between the retailer's utility function and the intensity $\lambda$ of its fairness concerns, we can determine the relationship between the retailer's utility function and the level $\beta$ of vertical competition as follows: when $0<\lambda<\omega /(1-\omega)$, we have $\partial U_{\mathrm{r}}^{\mathrm{F}} / \partial \beta<0$; when $\omega /(1-\omega)<\lambda$, we have $\partial U_{\mathrm{r}}^{\mathrm{F}} / \partial \beta>0$.
Proposition 5(i) shows that when the retailer has fairness concerns, the manufacturer's profit increases with the level of vertical competition in extended warranty service. Moreover, given Proposition 2, it can be seen that the retailer's fairness concerns do not change the way that the competition level influences the manufacturer's profit. On the other hand, as the retailer's fairness concern intensifies, the profits obtained by the manufacturer decrease. Considering Inference 2, the main reason for this situation is that in the face of increasing intensity of the retailer's fairness concerns, the manufacturer tends to lower product wholesale price so that the retailer receives indirect compensation. Another ideal solution for the manufacturer is to reduce extended warranty service price to attract consumers to purchase the service. In this case, a retailer that has a strong sense of fairness of concern may also choose to reduce extended warranty service price. However, the findings from the analysis of Proposition 4(i) show that retailers always offer extended warranties at a lower price than that of manufacturers. In summary, retailers' fairness concerns negatively affect the profit of manufacturers. The greater the intensity of the fairness concerns, the lower the profit of manufacturers.

Proposition 5(ii) shows that compared to the impact of vertical competition level on a retailer's performance without fairness concerns, an increase in vertical competition level in the context of the retailer's fairness concerns does not always enhance the utility of the retailer. When the intensity of the fairness concerns is lower than a certain threshold $\omega /(1-\omega)$, the utility of the retailer decreases with increasing vertical competition level, but the retailer's overall benefits increase with the intensity of the fairness concerns. This implies that a retailer can secure benefits by increasing the intensity of its fairness concerns. When the intensity of the retailer's fairness concerns is greater than the threshold $\lambda>\omega /(1-\omega)$, a counterintuitive conclusion is reached: the 
utility of the retailer is reduced if the intensity of its fairness concerns increases. This can be explained by the results from the analysis of Inference 2 and Proposition 4(iii). Superficially, increasing intensity of the fairness concerns can lead to a bigger difference in extended warranty service price, enabling the retailer to earn more from the extended warranty. However, an increase in the intensity of the fairness concerns beyond the threshold brings about a higher product retail price. This is not conducive to increasing the retailer's revenue from the product. Since product sales are the source of the revenue from extended warranties, the utility of the fair-minded retailer will decrease.

\section{Analysis with Numerical Examples}

To verify the propositions and inferences in Section 3, numerical examples are used to further analyse how the level $\beta$ of competition in extended warranty service between a manufacturer and a retailer and the intensity of the retailers fairness concerns $\lambda$ influence the pricing strategies of both parties for products and extended warranties. First, let $a=1$, $\lambda=1, \lambda_{0}=\lambda /(1+\lambda)=0.5$. The relationships between the manufacturer's product wholesale prices $w$ and $w^{\mathrm{F}}$ and the level $\beta$ of competition in extended warranty service can be determined in two situations: when the retailer has fairness concerns and when the retailer has no fairness concerns. These relationships are shown in Figure 2.

It can be seen from Figure 2 that the greater vertical competition in extended warranty service between the manufacturer and the retailer, the lower the product wholesale price of the manufacturer. If the vertical competition is weak, the wholesale price $w^{\mathrm{F}}$ when the retailer has fairness concerns is lower than the wholesale price $w$ when the retailer has no fairness concerns. If the vertical competition is strong, the wholesale price $w^{\mathrm{F}}$ when the retailer has fairness concerns is higher than the wholesale price $w$ when the retailer has no fairness concerns. As shown in Figure 2, when the retailer has fairness concerns, the manufacturer can determine product wholesale price based on the level of competition in extended warranty service between the two parties. The stronger the competition, the greater the wholesale price discount given to the retailer.

Figure 3 shows the relationship between the extended warranty service prices $p_{\mathrm{sm}}$ and $p_{\mathrm{sr}}$ of the manufacturer and retailer and the level $\beta$ of vertical competition in the extended warranty service without fairness concerns and the relationship between extended warranty service prices $p_{\mathrm{sm}}^{\mathrm{F}}$ and $p_{\mathrm{sr}}^{\mathrm{F}}$ of the manufacturer and retailer and the level $\beta$ of vertical competition in the extended warranty service when the retailer is fair-minded based on the above parameters.

As can be seen from Figure 3, regardless of whether the retailer is fair-minded, as the competition in extended warranty service between the manufacturer and retailer intensifies, both parties tend to raise the price of the service. And the greater the competition, the more obvious the rise in extended warranty service for both parties. This is consistent with Inferences 1 and 2 . When the retailer is not concerned about fairness, the manufacturer and retailer adopt the same extended warranty service pricing strategy.

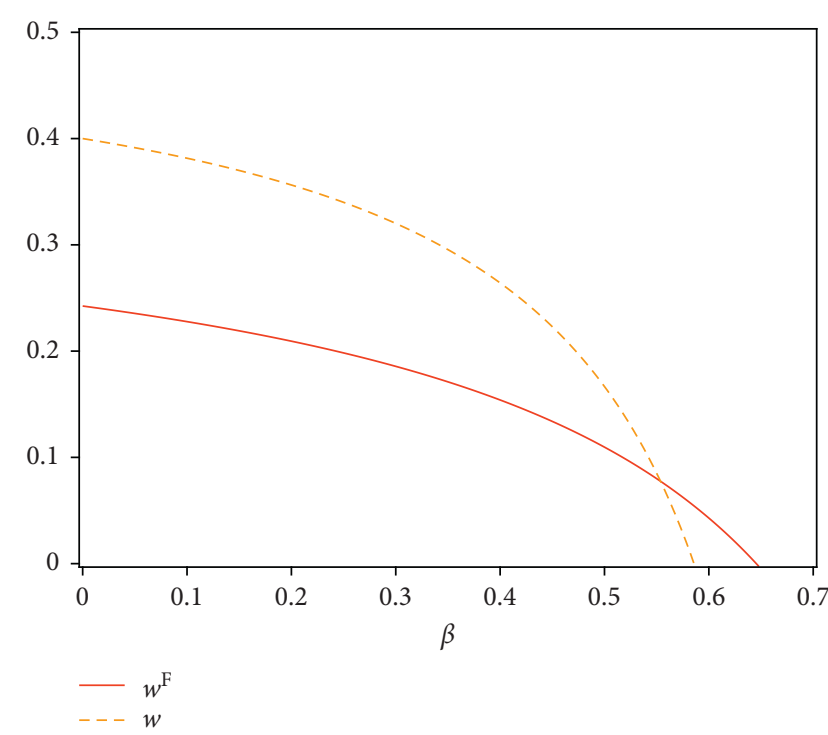

FIGURE 2: Relationships between wholesale prices $w$ and $w^{\mathrm{F}}$ and the level $\beta$ of vertical competition.

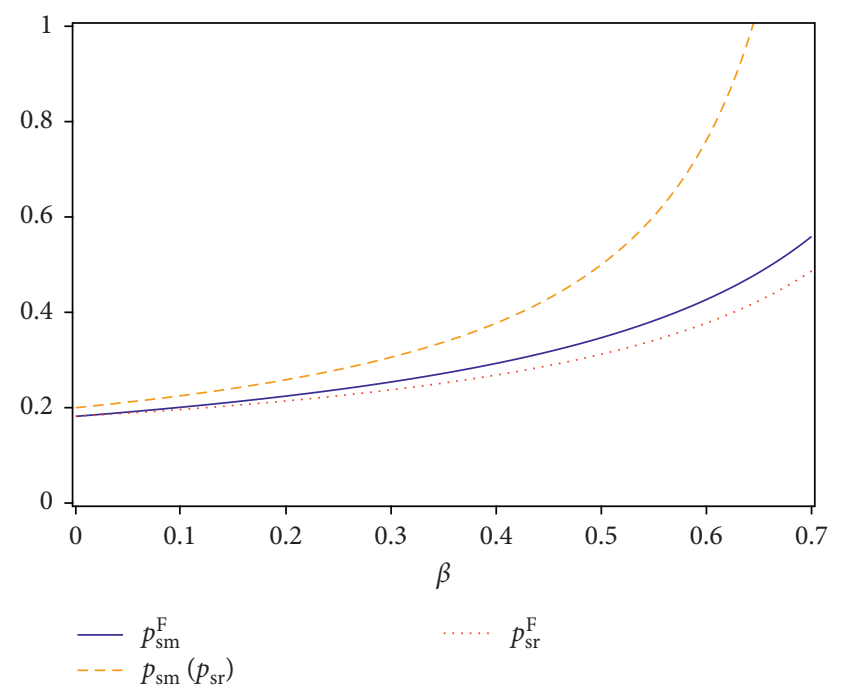

FIGURE 3: Relationships between extended warranty service prices $p_{\mathrm{sm}}, p_{\mathrm{sr}}, p_{\mathrm{sm}}^{\mathrm{F}}$, and $p_{\mathrm{sr}}^{\mathrm{F}}$ and $\beta$.

When the retailer has fairness concerns, the two parties adopt differential extended warranty service pricing strategies. In this case, the manufacturer's extended warranty service price is greater than that of the retailer. In addition, the extended warranty service price of both parties when the retailer has no fairness concerns is higher than the corresponding extended warranty service price when the retailer has fairness concerns. This result verifies Proposition 3. According to Figure 3, when the retailer has fairness concerns, the two parties can determine extended warranty service price based on the level of competition in the service. The stronger the competition, the greater the price difference in extended warranty service between the two parties. 
In the same way, let $a=1, \beta=0.5$. The relationships between the manufacturer's product wholesale price $w^{\mathrm{F}}$ and extended warranty service price $p_{\mathrm{sm}}^{\mathrm{F}}$ and the retailer's product sales price $p_{\mathrm{p}}^{\mathrm{F}}$ and extended warranty service price and $p_{\mathrm{sr}}^{\mathrm{F}}$ and the intensity $\lambda$ of the retailer's fairness concerns can be determined, as shown in Figure 4.

As can be seen from Figure 4, an increase in the intensity of the retailer's fairness concerns means a lower product wholesale price of the manufacturer, a higher sales price of the retailer, and a smaller difference in extended warranty service price between the two parties. Moreover, a decrease in the intensity of the retailer's fairness concerns will widen the gap between the wholesale price and sales price and between the extended warranty service price of the manufacturer and retailer. These refsults prove Inference 2 and Proposition 4. From Figure 4, it is clear that when the intensity of the retailer's fairness concerns increases, the retailer can make a larger profit on each item sold and enjoy a greater price advantage in the extended warranty service market. This price advantage also helps the retailer increase its revenue.

Following the above method of assigning values to exogenous parameters, let $a=1, \lambda=1, \lambda_{0}=\lambda /(1+\lambda)=0.5$. The relationships between the two parties' profits or utilities $\pi_{\mathrm{r}}, U_{\mathrm{r}}, \pi_{\mathrm{m}}$, and $\pi_{\mathrm{m}}^{\mathrm{F}}$ and the level $\beta$ of their competition in extended warranty service can be determined in two situations: when the retailer has fairness concerns and when the retailer has no fairness concerns. These relationships are shown in Figures 5(a) and 5(b).

As can be seen from Figures 5(a) and 5(b), regardless of whether the retailer has fairness concerns, the profits or utilities of the manufacturer and retailer increase with the level of competition in an extended warranty service. In addition, the greater the competition is, the faster the profits or utilities of the manufacturer and retailer grow. This suggests that the competition in an extended warranty service between the two parties is beneficial to both parties. The result proves Proposition 2 and Proposition 5(i).

Let $a=0.5$ and $\beta=0.9$. The revenue of the manufacturer when the retailer has fairness concerns and when the retailer has no fairness concerns is shown in Figure 6.

It can be seen from Figure 6 that when the retailer has fairness concern preference, its greater fairness concerns means a lower revenue of the manufacturer, leading to a wider income gap compared with when the retailer has no fairness concern preference. This verifies Proposition 5(i). As can be seen from Figure 6, the retailer's fairness concerns are always unfavourable to the manufacturer, and the stronger the intensity of the retailer's fairness concerns, the lower the manufacturer's revenue.

In the above parameter settings, the relationship between the utility $U_{\mathrm{r}}$ of the retailer and the intensity $\lambda$ of its fairness concerns can be further obtained as shown in Figure 7.

As can be seen from Figure 7(a), when the intensity of the retailer's fairness concerns is low and increases, the utility of the retailer gradually increases, and the greater the intensity is, the faster the utility grows. This indicates that the retailer can benefit itself from increasing the intensity of its fairness concerns. As shown in Figure 7(b), when the

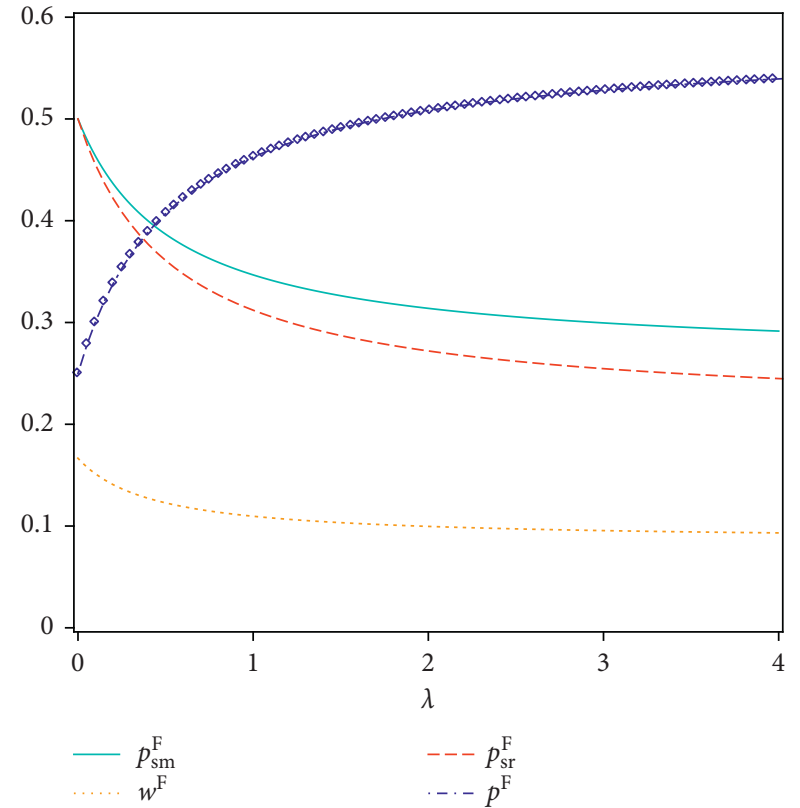

FIgURE 4: Relationships between product wholesale price $w^{\mathrm{F}}$, product sales price $p_{\mathrm{p}}^{\mathrm{F}}$, extended warranty service price $p_{\mathrm{sm}}^{\mathrm{F}}, p_{\mathrm{sr}}^{\mathrm{F}}$, and $\lambda$.

intensity of the retailer's fairness concerns is high and rises, the utility of the retailer gradually decreases. Moreover, the greater the intensity, the slower the decrease in the retailer's utility. This means that as the retailer increases the intensity of its fairness concerns beyond a certain threshold, its benefit is reduced. This result provides evidence supporting Proposition 5(ii). From Figure 7, it is clear that it is not always beneficial for a retailer to increase the intensity of its fairness concerns. Only when the intensity increases are within a certain threshold can they bring a higher utility for the retailer.

\section{Conclusions}

As the product service market grows rapidly, both manufacturers and retailers have begun to provide extended warranties. Consumers can choose to purchase an extended warranty service from either the manufacturer or the retailer. Since the manufacturers and retailers in a supply chain provide homogeneous extended warranties services, they face competition with each other. At the same time, besides considering its own earnings, a retailer pays attention to the distribution of profits in the supply chain. A lower-thanexpected profit can lead the retailer to have fairness concern preferences. This paper proposes a manufacturer-led Stackelberg game model to investigate optimal pricing strategies of manufacturers and retailers for their products and extended warranty services when the retailer's fairness concern preference. This paper further analyses how the level of vertical competition in extended warranty service and the intensity of a retailer's fairness concerns influence the optimal pricing of products and extended warranties and profits for the manufacturer and retailer. 


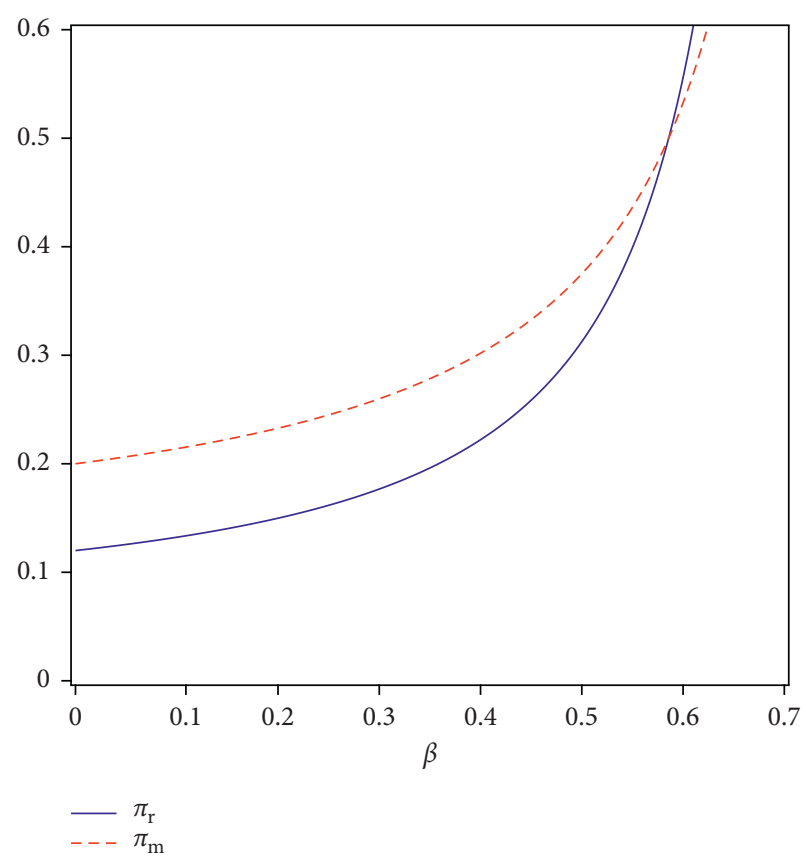

(a)

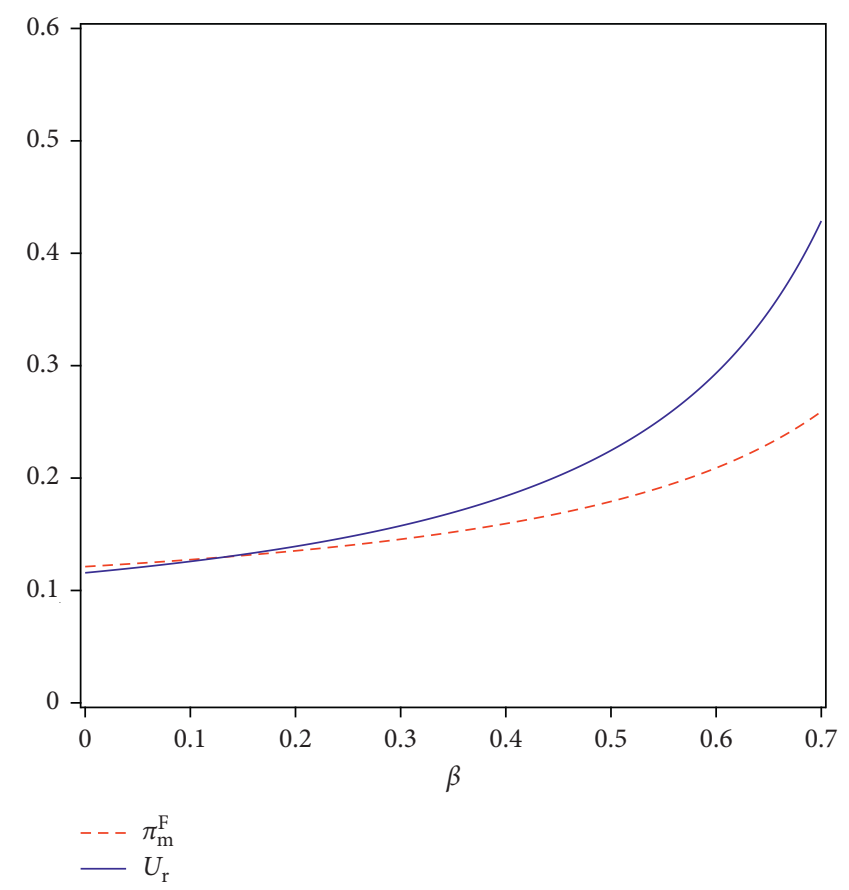

(b)

Figure 5: (a) Relationships between $\pi_{\mathrm{r}}, \pi_{\mathrm{m}}$, and $\beta$; (b) Relationships between $U_{\mathrm{r}}, \pi_{\mathrm{m}}^{\mathrm{F}}$, and $\beta$.

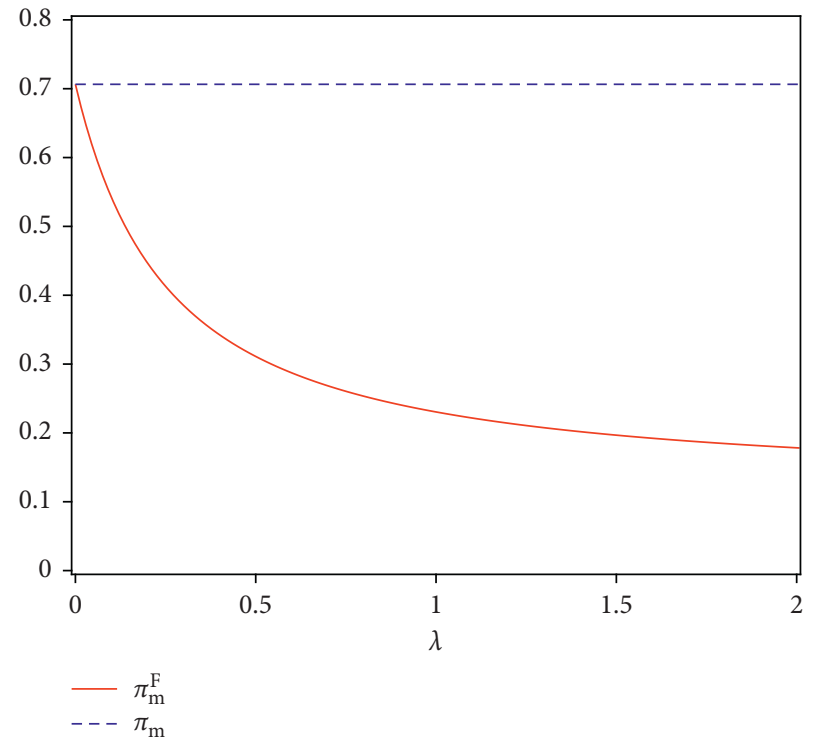

Figure 6: Relationships between $\pi_{\mathrm{m}}, \pi_{\mathrm{m}}^{\mathrm{F}}$, and $\lambda$.

This paper presents the following findings. Firstly, when the retailer has no fairness concerns, the retailer and the manufacturer share the same optimal extended warranty service pricing strategies. And increasing competition in extended warranty service between the two parties leads to a higher consistent extended warranty service price and a lower retail price. In contrast, when the retailer has fairness concerns, the retailer and the manufacturer develop differential pricing strategies for an extended warranty service as their optimal choice. In this case, the manufacturer tends to set an extended warranty service price higher than that of the retailer to surrender part of its profits to the retailer and offset the retailer's concern about unfairness. Secondly, the difference in extended warranty service price between the two parties is affected by the level of competition in the extended warranty service and the intensity of the retailer's fairness concerns. Increase in vertical competition in an extended warranty service will always widen the price gap 


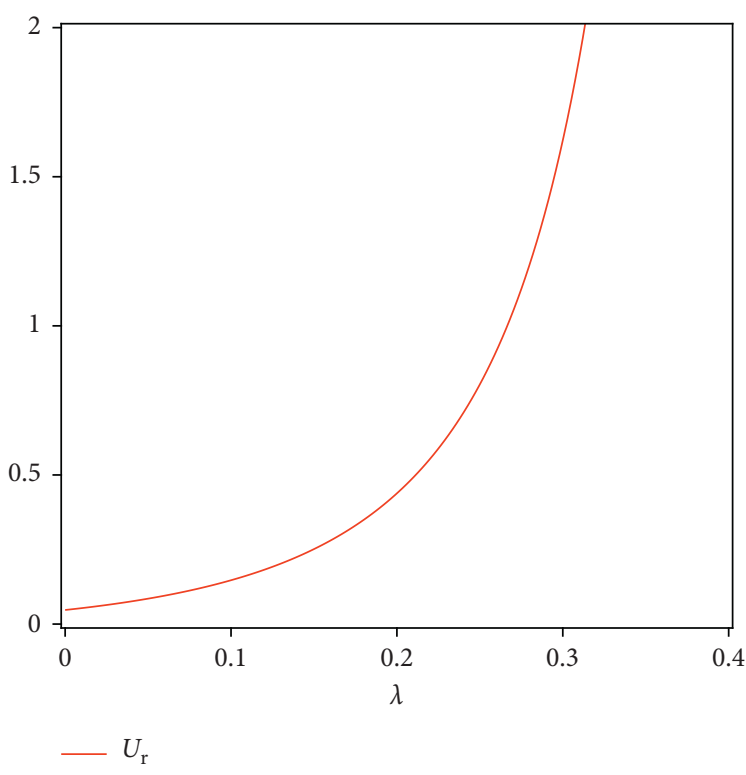

(a)

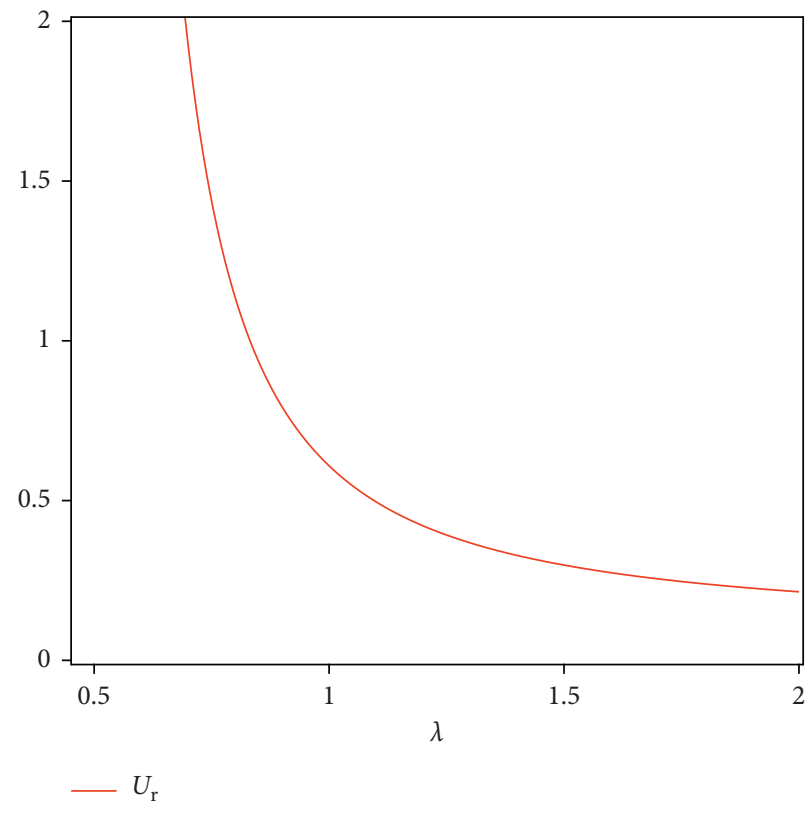

(b)

FIGURE 7: Relationship between the retailer's utility $U_{\mathrm{r}}$ and the intensity $\lambda$ of fairness concerns. (a) The influence of the intensity of fairness concerns on utility when the intensity is lower. (b) The influence of the intensity of fairness concerns on utility when the intensity is higher.

in the extended warranty service between the manufacturer and retailer. The impact of the intensity of the retailer's fairness concerns on this price gap depends on the intensity itself. When the intensity of the retailer's fairness concerns is less than a certain threshold, an increase in the intensity of the fairness concerns will narrow the price gap in the extended warranty service between the manufacturer and retailer. When the intensity of the retailer's fairness concerns is greater than the threshold, increasing intensity of the fairness concerns implies a greater difference in extended warranty service price between the two parties. Thirdly, the results from further analysis of the profit of both parties show that when the retailer has no fairness concerns, its competition with the manufacturer in extended warranty service will increase the income of both parties, rather than harming their interests. In comparison, a higher intensity of the retailer's fairness concerns always harms the interests of the manufacturer. For the retailer, only when the intensity increases are within a certain threshold can it improve its utility.

This paper considers vertical competition in extended warranty service in a product and service supply chain consisting of only one retailer and one manufacturer. In reality, a manufacturer may also distribute the same product through multiple retailers, which may experience horizontal competition in an extended warranty service with each other. This issue can be further examined through vector equalization [30-32]. Future research can be done on pricing strategies in a product and service supply chain involving multiple retailers competing with each other horizontally in an extended warranty service in the context of fairness concerns.

\section{Data Availability}

The data generated and/or analysed during the current study are available from the corresponding author on reasonable request.

\section{Conflicts of Interest}

The authors declare no conflicts of interest.

\section{Acknowledgments}

This research was funded by the National Key Research and Development Program (grant no. 2018YFB1701502), the National Natural Science Foundation of China (grant nos. 71572020 and 71501162), the Chongqing Basic Science and Frontier Technology Research Project (grant no. cstc2016jcyjA0528), the Scientific and Technological Research Program of Chongqing Municipal Education Commission (no. KJQN201800715), the China Postdoctoral Science Foundation (grant no. 2015M580770), the Humanities and Social Science Research Program of Chongqing Municipal Education Commission (grant no. 19SKGH061), and the Chongqing Postdoctoral Science Foundation (grant no. Xm2015044).

\section{References}

[1] J.-C. Lu, Y.-C. Tsao, and C. Charoensiriwath, "Competition under manufacturer service and retail price," Economic Modelling, vol. 28, no. 3, pp. 1256-1264, 2011. 
[2] J. C. Hartman and K. Laksana, "Designing and pricing menus of extended warranty contracts," Naval Research Logistics, vol. 56, no. 3, pp. 199-214, 2009.

[3] T. Chen, A. Kalra, and B. Sun, "Why do consumers buy extended service contracts?," Journal of Consumer Research, vol. 36, no. 4, pp. 611-623, 2009.

[4] X. Chen and X. Wang, "Free or bundled: channel selection decisions under different power structures," Omega, vol. 53, pp. 11-20, 2015.

[5] X. Chen, X. Wang, and H. K. Chan, "Manufacturer and retailer coordination for environmental and economic competitiveness: a power perspective," Transportation Research Part E: Logistics and Transportation Review, vol. 97, pp. 268-281, 2017.

[6] T. H. Cui, J. S. Raju, and Z. J. Zhang, "Fairness and channel coordination," Management Science, vol. 53, no. 8, pp. 1303-1314, 2007.

[7] N. Jack and D. N. P. Murthy, "A flexible extended warranty and related optimal strategies," Journal of the Operational Research Society, vol. 58, no. 12, pp. 1612-1620, 2007.

[8] S. Bouguerra, A. Chelbi, and N. Rezg, "A decision model for adopting an extended warranty under different maintenance policies," International Journal of Production Economics, vol. 135, no. 2, pp. 840-849, 2012.

[9] K. Shahanaghi, R. Noorossana, S. G. Jalali-Naini, and M. Heydari, "Failure modeling and optimizing preventive maintenance strategy during two-dimensional extended warranty contracts," Engineering Failure Analysis, vol. 28, pp. 90-102, 2013.

[10] B. Jiang and X. Zhang, "How does a retailer's service plan affect a manufacturer's warranty?," Management Science, vol. 57, no. 4, pp. 727-740, 2011.

[11] H. S. Heese, "Retail strategies for extended warranty sales and impact on manufacturer base warranties," Decision Sciences, vol. 43, no. 2, pp. 341-367, 2012.

[12] K. Li, S. Mallik, and D. Chhajed, "Design of extended warranties in supply chains under additive demand," Production and Operations Management, vol. 21, no. 4, pp. 730-746, 2012.

[13] M. A. Cohen and S. Whang, "Competing in product and service: a product life-cycle model," Management Science, vol. 43, no. 4, pp. 535-545, 1997.

[14] X. Chen, X. Wang, and Y. Xia, "Production coopetition strategies for competing manufacturers that produce partially substitutable products," Production and Operations Management, vol. 28, no. 6, pp. 1446-1464, 2019.

[15] Y. Bian, S. Yan, W. Zhang, and H. Xu, "Warranty strategy in a supply chain when two retailer's extended warranties bundled with the products," Journal of Systems Science and Systems Engineering, vol. 24, no. 3, pp. 364-389, 2015.

[16] C. Camerer and R. H. Thaler, "Anomalies: ultimatums, dictators and manners," Journal of Economic Perspectives, vol. 9, no. 2, pp. 209-219, 1995.

[17] T.-H. Ho and J. Zhang, "Designing pricing contracts for boundedly rational customers: does the framing of the fixed fee matter?," Management Science, vol. 54, no. 4, pp. 686-700, 2008.

[18] O. Caliskan-Demirag, Y. Chen, and J. Li, "Channel coordination under fairness concerns and nonlinear demand," European Journal of Operational Research, vol. 207, no. 3, pp. 1321-1326, 2010.

[19] X. Wu and J. Niederhoff, "Fairness in selling to the newsvendor," Production and Operations Management, vol. 23, no. 11, pp. 2002-2022, 2014.
[20] P. Ma, K. W. Li, and Z.-J. Wang, "Pricing decisions in closedloop supply chains with marketing effort and fairness concerns," International Journal of Production Research, vol. 55, no. 22 , pp. 6710-6731, 2017.

[21] Y. Zhou, M. Bao, X. Chen, and X. Xu, "Co-op advertising and emission reduction cost sharing contracts and coordination in low-carbon supply chain based on fairness concerns," Journal of Cleaner Production, vol. 133, pp. 402-413, 2016.

[22] W. Liu, S. Wang, D. Zhu, D. Wang, and X. Shen, "Order allocation of logistics service supply chain with fairness concern and demand updating: model analysis and empirical examination," Annals of Operations Research, vol. 268, no. 1-2, pp. 177-213, 2018.

[23] N. Du and Q. L. Han, "Pricing and service quality guarantee decisions in logistics service supply chain with fairness concern," Asia-Pacific Journal of Operational Research, vol. 35, no. 5, article 1850036, 2018.

[24] N. Wang, Z.-P. Fan, and X. Chen, "Effect of fairness on channel choice of the mobile phone supply chain," International Transactions in Operational Research, 2019, In press.

[25] Q. H. Li and B. Li, "Dual-channel supply chain equilibrium problems regarding retail services and fairness concerns," Applied Mathematical Modelling, vol. 40, no. 15-16, pp. 7349-7367, 2016.

[26] X. Chen, L. Li, and M. Zhou, "Manufacturer's pricing strategy for supply chain with warranty period-dependent demand," Omega, vol. 40, no. 6, pp. 807-816, 2012.

[27] B. Dan, S. Zhang, and M. Zhou, "Strategies for warranty service in a dual-channel supply chain with value-added service competition," International Journal of Production Research, vol. 56, no. 17, pp. 5677-5699, 2018.

[28] X. Zhang, X. Han, X. Liu, R. Liu, and J. Leng, "The pricing of product and value-added service under information asymmetry: a product life cycle perspective," International Journal of Production Research, vol. 53, no. 1, pp. 25-40, 2015.

[29] H. Fu, K. L. Teo, Y. Li, and L. Wang, "Weather risk-reward contract for sustainable agri-food supply chain with lossaverse farmer," Sustainability, vol. 10, no. 12, p. 4540, 2018.

[30] X. Sun, H. Fu, and J. Zeng, "Robust approximate optimality conditions for uncertain nonsmooth optimization with infinite number of constraints," Mathematics, vol. 7, no. 1, p. 12, 2019.

[31] X.-K. Sun, X.-J. Long, H.-Y. Fu, and X.-B. Li, "Some characterizations of robust optimal solutions for uncertain fractional optimization and applications," Journal of Industrial \& Management Optimization, vol. 13, no. 2, pp. 803-824, 2017.

[32] X. Sun, K. L. Teo, and L. Tang, "Dual approaches to characterize robust optimal solution sets for a class of uncertain optimization problems," Journal of Optimization Theory and Applications, vol. 182, no. 3, pp. 984-1000, 2019. 


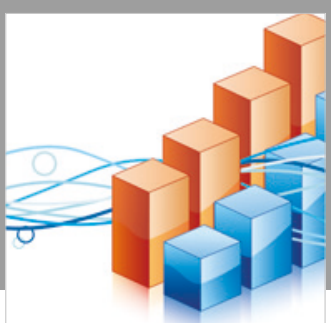

Advances in

Operations Research

\section{-n-m}
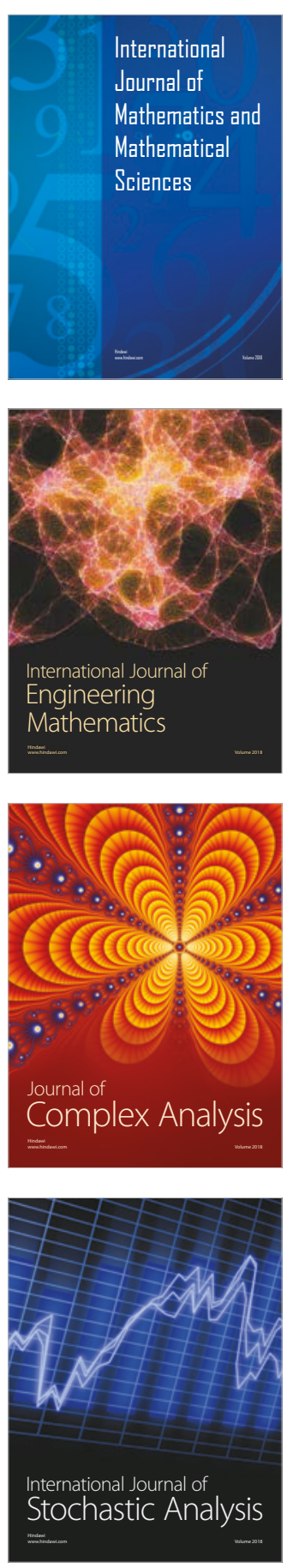
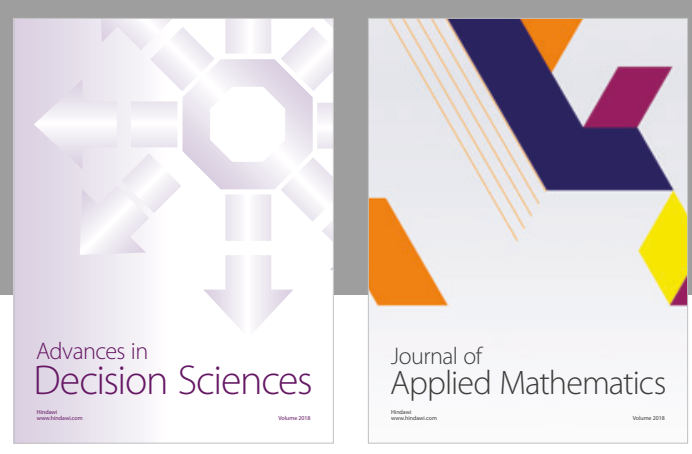

Journal of

Applied Mathematics
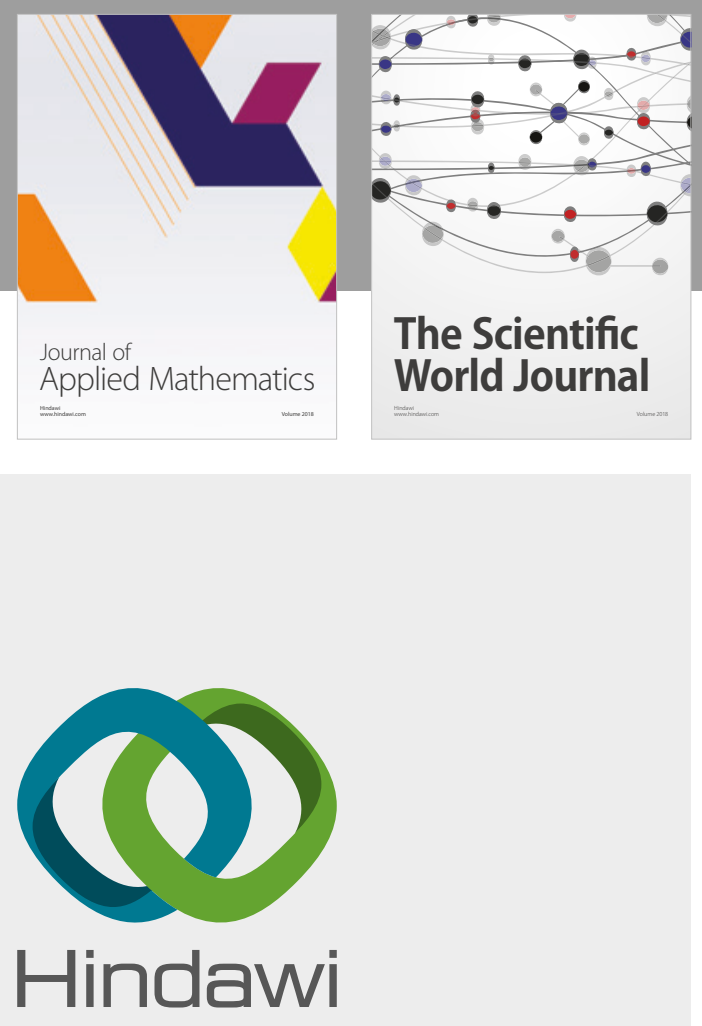

Submit your manuscripts at

www.hindawi.com

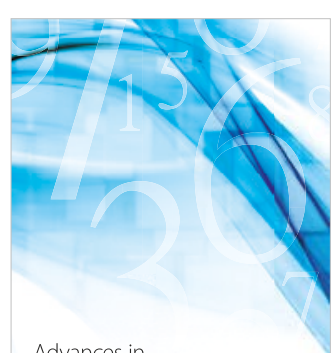

Advances in
Numerical Analysis
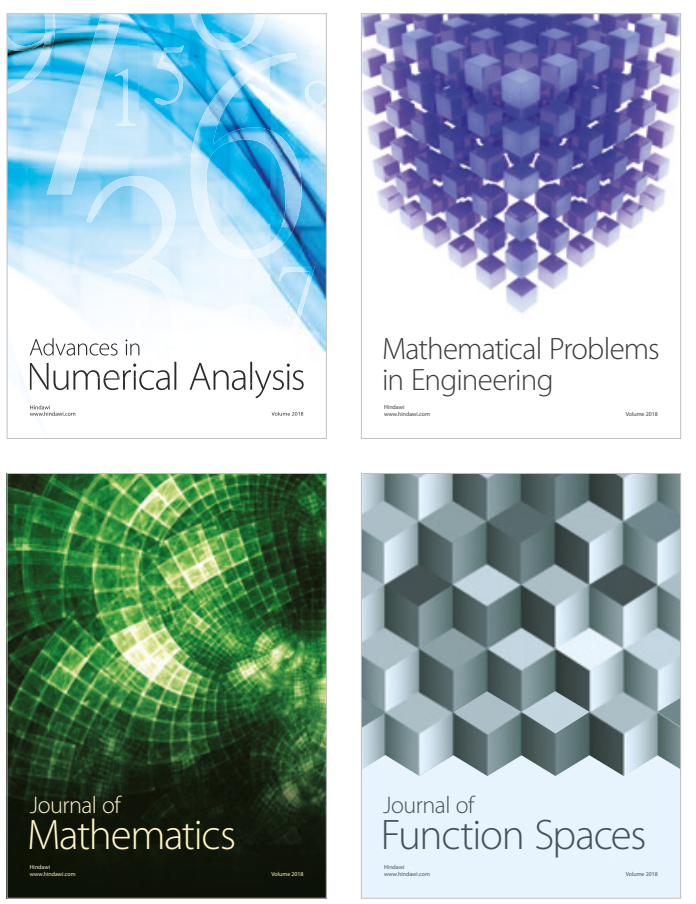

Mathematical Problems in Engineering

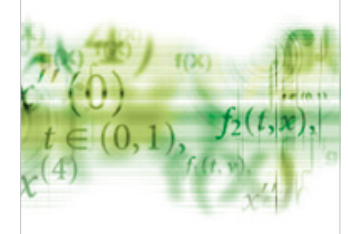

International Journal of

Differential Equations

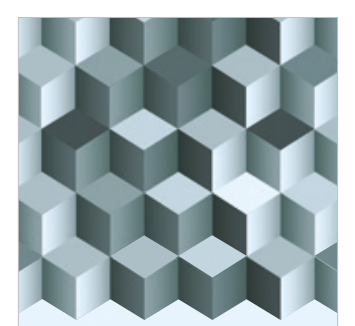

Journal of

Function Spaces

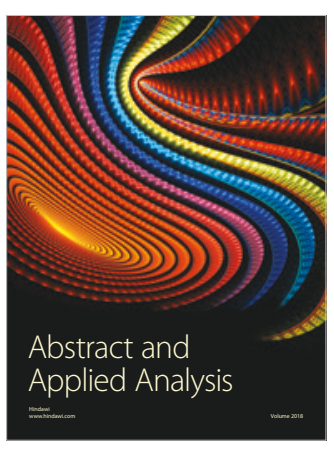

The Scientific

World Journal

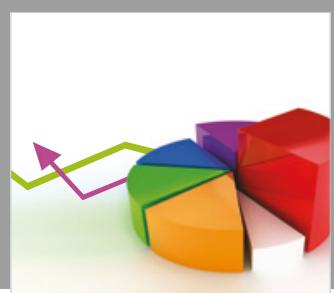

Journal of

Probability and Statistics
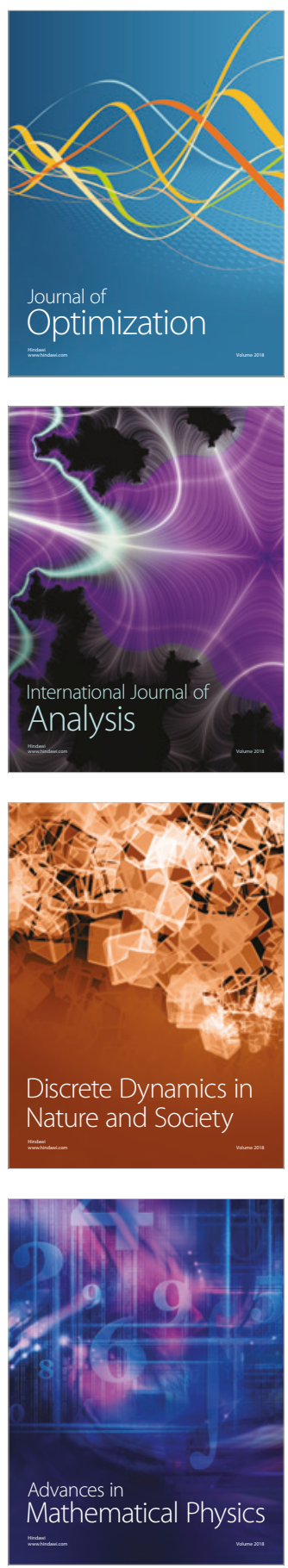